\title{
tendencias actuales en la construcción de maquinaria para la fabricación de cemento
}

\author{
Conferencia de la reunión de la Asociación Alemana \\ de Fábricas de Cemento el 13 de Septiembre de 1960 en Salzburgo
}

(«Zement-Kalk-Gips», febrero 1961, pág. 41.)

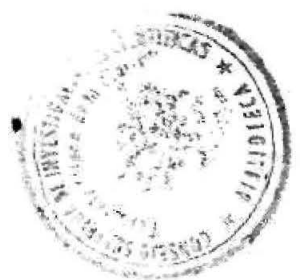

A. BELLWINKEL

\section{Introducción}

La producción de la industria alemana del cemento en la Zona Occidental ha experimentado un gran desarrollo en el pasado año. El aumento de un $23 \%$, aproximadamente, en la venta de elementos de construcción motivó un incremento de un $18 \%$ en el consumo de productos de la industria del cemento, en comparación con el año anterior. Comparado con el crecimiento normal del 9,8\% en Ejercicios anteriores, este aumento presenta unas exigencias anormales frente a la capacidad de producción de las fábricas. Este efecto resultó ser más considerable en la Zona sur de Alemania con un $23 \%$, mientras que en la Zona norte solamente se apreció un 13,5\% de aumento. Este desarrollo inesperado hizo que las fábricas de cemento, que en los años 1956 al 1959 habían montado nuevos hornos con un aumento de, aproximadamente, un millón de toneladas al año en la producción, se vieran ante la necesidad de ampliar su capacidad a marchas aceleradas. Si consideramos, por otra parte, los viejos hornos que se hallaban todavía en funcionamiento desde hace más de cincuenta años, no nos puede asombrar que en la época 1959-60 se encontrasen en construcción hornos para una producción equivalente a 3 millones de toneladas por año de producción de clínker, considerándose, al mismo tiempo, que en el presente año tengan lugar pedidos para otras unidades de hornos. Como al mismo tiempo deben adquirirse nuevas instalaciones de trituración y de mo'ienda, así como también otros dispositivos, aparece una necesidad de maquinaria para la industria del cemento de Alemania occidental en una medida no conocida hasta la fecha, que sobrepasa ampliamente las inversiones del año 1959: aproximadamente en 150 millones de DM. Bajo estas circunstancias se han realizado proyectos en todas las fábricas, y todavía se están realizando estudios con objeto de apreciar la tendencia que se refleja en el desarrollo de la maquinaria para el cemento.

\section{Influencias sobre el desarrollo}

Primeramente vamos a considerar los influjos a los que se encuentra sometido el desarrollo de la maquinaria del cemento.

Las 95 fábricas de cemento de la Alemania Occidental aparecen distribuídas con mucha uniformidad en toda la Zona Federal alemana. Las relaciones conocidas del mercado originan, en consecuencia, en primer lugar, una competencia en lo que respecta a calidades. Esta lucha exige una preparación cuidadosa de las materias primas para la elaboración de un clínker bueno, con el fin de poder conseguir un cemento uniforme y de elevada calidad. 
Las extgencias que se fijan para los dispositivos mecánlcos se refleren, principalmente, a los dtspositivos dosiflcadores, a los dispositivos de mezcla y, también, a los aparatos de molienda, elementos todos que, justamente por los motivos indicados, han sufrido un desarrollo técnico especial. Al mismo tiempo se realiza una amplla racionalización, ya que, de lo contrario, no hubłera sido poslble mantener hoy día el precio de la producción de cemento, que, según el índice del año 1957, era de 214 (calculado sobre la base de 1938), en oposición al caso del carbón, nuestro combustible mas importante, cuyo indice ha aumentado en el mismo tiempo de 378 a 402.

La República Federal tiene precios más elevados en los combustibles en comparación con los paises nórdicos vecinos, con un coste de explotación superior en más de un $40 \%$; y, en consecuencia, se ha fomentado especialmente el desarrollo de los sỉstemas de hornos. En nuestras fábricas se han creado hornos Lepol, precalentadores de gases, calcinadores y concentradores, como también hornos verticales de alto rendimlento, elementos todos ellos que son actualmente de tnterés general para la industria del cemento en todo el mundo. Los efectos del elevado coste de los combustibles en las fábricas que trabajan con la via húmeda es preciso tenerlos muy en cuenta.

Puede apreciarse que existe una reducción en la prođucción de cemento por via húmeda, incluso en los casos más favorables de hornos con un consumo de combustible superior en un $40-50 \%$ a los de via seca. La proporción anterlor de fábricas de via húmeda (un total de 11), que representaba aproximadamente un $25 \%$ de la producción de Alemania, se ha reducido en el último año a un $22 \%$, y todavía sufrirá un descenso mayor. Cuando, por la naturaleza de las materias primas, no es posible desligarse del proceso de via húmeda, por tenerse que separar el pedernal o los guijarros de la greda por el procedimiento de la pasta, resulta lóglca una transformación o reforma al procedimiento de via seca (2) (con un remanente de humedad de 15 a $18 \%$ ) por la que ya se han decidido tres fábrlcas; otras fábricas estudian detenidamente este problema. Una tendencia simflar se observa también en Inglaterra, país clásico en el procedimiento de vía húmeda. Incluso en los Estados Unldos, donde hasta 1945 se trabajaba exclusivamente con instalaciones de vía hǘmeda, se pasó al procedimfento de vía seca en forma creciente después de la última guerra mundial, por haberse convencido que empleando modernas instalaciones para la mezcla y homogeneización de crudos pueden obtenerse cementos de igual calidad con la vía seca (3). A pesar de esto, en los Etstados Unidos, un 55 a $60 \%$ de las fábricas todavía trabajan por la via húmeda con un consumo medio de $2.150 \mathrm{kcal} / \mathrm{kg}$ de clinker, frente a $1.200-1.700 \mathrm{kcal} / \mathrm{kg}$ de clínker en la República Federal Alemana.

La preparación más cuidadosa de las materias primas exige una mollenda más flna y una homonegeización mejor antes de efectuar la cocclón, lo que representa, además de un desgaste mecánico mayor, un aumento en el número de $\mathrm{kWh}$ por tonelada de cemento, sl el desarrollo de procedimientos y maquinaria no nos ofrece un ahorro de energia. Esto no solamente afecta a los nuevos dispositivos para la preparación đe los crudos, sino también a los de preparación de cemento. Las fábricas que disponen de materlas primas favorables trabajan actualmente con un consumo de 75 a $80 \mathrm{kWh}$ por tonelada de cemento, pero simultáneamente existen consumos de 120 a $140 \mathrm{kWh}$ por tonelada de cemento, cuando se trabaja con materlales duros y escorias siderúrgicas; estos valores no deben asustarnos si tenemos en cuenta el consumo medio de los Estados Unidos, que es de $145 \mathrm{kWh}$ por tonelada.

En relación con los gastos de fabricación, debe también considerarse de notable importancia la mano de obra, aunque su influencla sea menor.

El numero de empleados en la industria del cemento alemana es de 21.500 personas aproximadamente, lo que representa una productividad de unas 1.100 toneladas/hombre/año; por cada tonelada de cemento se tienen que considerar dos horas de trabajo aproximadamente. Esto resulta, sin duda, elevado, frente a las cifras de Estados Unidos, donde en 1957 se obtuvo una media de 1,4 horas por tonelada-3,75 h/t como valor más desfavorable $\mathrm{y} 0,8 \mathrm{~h} / \mathrm{t}$ como mejor rendimiento- (3). Sl consideramos los gastos de un trabajador alemán en unos 8.000 DM por año, el coste por salarlos en la producción de cemento resulta ser superior a 7,50 DM por tonelada. Como el salario de nuestra industria aumenta, en proporción, más de prisa que la productividad, este punto se debe tener en cuenta como muy importante en el proyecto y construcción de la nueva maquinaria. Otra influencia sobre el desarrollo aparece motivada por la falta de mano de obra; los operarios exigen condiciones de mayor facllidad y comodidad en el trabajo, es decir, disponer de naves de trabajo exentas de polvo $y$ sin exposición a un calor y ruido excesivos.

Por parte đel Estado (disposiciones oflclales) se fljan exigencias que tienen cierta influencia en el desarrollo de la maquinaria. En los últimos affos, además del funcionamiento continuo de las 
instalaciones de hornos, trabajaban tamblén las instalaciones de los moltnos durante los domtngos, porque el personal de control resultaba reducido y las reparaciones que se efectuaban entre semana precisaban más personal y especialistas, ya que durante los domingos el trabajo no se tenia que realizar. Esta ocupación de los operarlos, los sábados, los domingos y días festivos, se va a limitar todavia más, si se considera que en adelante se dispondrá únicamente de un horario de trabajo por semana de cuarenta horas. Todo esto no puede dejar de considerarse en los dispositivos mecánicos de las fábricas y debe conducir a una más amplia automatízación de las instalaciones. Tampoco se deben olvidar las disposiciones cada día más severas para conservar puro el aire $y$ proteger los contornos de la fábrica frente a cualquier tipo de emisiones.

La capacidad acertada del rendimiento para la nueva maquinaria no se determina únicamente por la amplitud de la fábrica, si se toma como condictón que las posibllidades de venta y la inversión de capital no pueden determinar, por sí mismas, el tipo de la maquinaria. En la República Federal Alemana predominan las fábricas pequeñas: aproximadamente 50 fábricas producen menos de $200.000 \mathrm{t}$ de cemento al año; 20 , menos de $100.000 \mathrm{t}, \mathrm{y} 15$ fábricas, más de $400.000 \mathrm{t}$. La fábrica más grande ha producido en el último año 1.600 .000 t de cemento, aproximadamente. Hay muchos puntos de vista cuando se tiene que estudiar cuál debe ser la capacidad de una nueva máquina. De Ios hornos pedidos en el pasado año, solamente dos son para una capacidad de 400 toneladas/día. La mayoría de ellos se han proyectado para 500 a 800 toneladas, y las fabricas mayores, que tienen una producción anual de más de 600.000 toneladas, disponen de hornos con un rendimiento por día de 800 a 1.000 toneladas. En lo que se refiere a las instalaciones de molienda, en la última temporada ya no se han construfdo molinos para crudo y para cemento con un rendimiento inferior a 15 toneladas/hora. Las fábricas mayores se han decidido por nuevos mollnos de cemento de 80 toneladas/hora e instalaciones dé molienda $\mathrm{y}$ secado de 100 toneladas/hora.

Estas disposiclones permiten apreciar que en las fábricas pequeñas se debe disponer de una nueva capacidad que pueda sustituir por lo menos la mitad de la producción obtenida hasta ahora. Al aparecer un aumento en la producción las fábricas podrán trabajar todavia con las máquinas antiguas, aunque considerando un coste más elevado en la fabricación. Si la situación en el mercado desciende, entonces las fábrlcas pueden trabajar con las máquinas modernas con un coste más bajo en la producción. Esto concuerda en todas las fábricas muy pequeñas, ya que son fábricas con hornos verticales $\mathrm{y}$, actualmente, existe una posibilidad de ampllación de unas 50.000 toneladas al introducir un horno vertical moderno de alto rendimiento. Las fábricas mayores se han decldido, hace dos o tres años, por las unldades mayores que construye la industria de la maquinaria.

La distinta capacidad de rendimiento de las diversas fabricas origina una gran varledad de hornos $\mathrm{y}$ de instalaciones de molienda que complica la vida a nuestra industria de maquinaria. Esta no tiene una vida tan fácil como, por ejemplo, las fábricas de maquinaria de la industria rusa del cemento. En este país, y según un informe muy interesante sobre la Unlón Sovtética de B. Nikander, solamente se construyen tres tipos de hornos para via húmeda con un rendimiento de $850,1.200$ y 1.700 toneladas por día, y para la vía seca (que se emplea únicamente en un $15 \%$ para las nuevas instalaciones) solamente existe un tipo de horno con un rendimlento de 1.200 toneladas por día.

La Instalación de cocción es el corazón de una fábrica y a ella se tienen que adaptar las restantes instalaclones de maquinaria y los restantes dispositivos. Las plantas corrientes hasta ahora prevến un almacén central de materlales (silo-hangar), equipado con un puente-grúa, y próximos a él, los hornos y los departamentos de molienda. Las instalaciones de puentes-grúa requleren slempre reparaclones y precisan una conservación, necesitándose además un clerto número de personal. En las nuevas fábricas la nave se construye con descarga de fondo, por la que el material cae automáticamente a las cintas transportadoras para ser transportado a los depósitos o silos de la instalación de mollenda. Estos dispositivos de transporte se pueden automatizar con relativa facilidad y resultan muy útiles cuando, con el fln de poder aprovechar el calor del horno, se tiene que secar el crudo los domingos y los dias festivos 0 , también, cuando las instalaciones de mollenda tienen que trabajar los domingos o durante la noche sin personal de servicio.

La disposición prematura que permite este proyecto prolonga ciertamente los transportes; pero debe considerarse, por otra parte, que un material en forma de polvo puede transportarse por los canales neumáticos a grandes distancias con un esfuerzo reducido, lo mismo que el material en forma de grano por transportadores de cinta. Los gastos de conservación de ambos dispositivos de transporte son reducidos. 

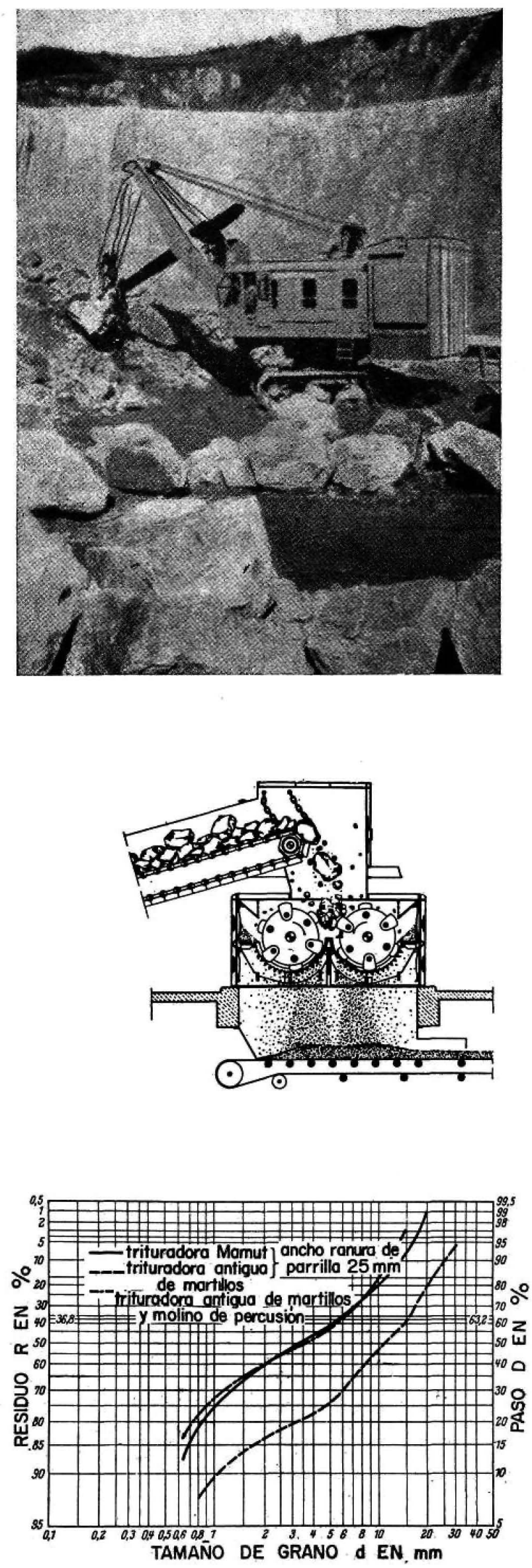

El control eléctrico de las máquinas y de los aparatos de transporte ha sufrido una gran simplificación con la televisión industrial (5), resultando posible hoy día con su ayuda el trabajo en colaboración de diferentes zonas de la instalación aun cuando éstas se encuentren distantes entre sí (6).

A continuación trataremos sobre el desarrollo de la maquinaria en relación con los diferentes departamentos de las fábricas de cemento.

\section{Explotación de materias primas}

Nuestras canteras se encuentran en reforma para un funcionamiento de cinco días, con el fln de obtener en este tiempo el material necesario para la semana, lo, que, por otra parte, requiere la aplicación de nuevos métodos de explotación (7). Donde las condiciones de la cantera lo permiten se realizan voladuras con grandes perforaciones (8), empleando perforadoras giratorias o de percusión de gran potencia (9). La evacuación del material en grandes trozos del frente de la explotación se realiza en coordinación con la instalación de trituración, que por su parte debe encontrarse en la misma cantera $\mathrm{y}$, si es posible, a una distancia no muy grande del frente de la explotación.

La pala-excavadora (10) (fig. 1), accionada eléctricamente en la mayor parte de los casos, carga el material. El transporte por carriles a la instalación de trituración debe cambiarse, cuando las condiciones del terreno lo permitan, por un transporte con camiones-volquete de gran capacidad de carga (11), pues éstos, sin diflcultad alguna, pueden seguir el desplazamiento de la excavadora y descargar el material directamente en la tolva de alimentación de la instalación de trituración.

Fig. 1.-Pala excavadora accionada eléctricamente (casa DEMAG).

Fig. 2.-Trituradora de martillos (easa MIAG).

Fig. 3.-Comparación de las curvas granulométricas; las dos fases de las trituradoras antiguas de martillos $y$ una fase de la trituradora Mamut (Hirschmann). 
Las palas-excavadoras que se encuentran delante del frente de explotación deben ser apoyadas en el trabajo por máquinas para el arrastre y recogida de material. Para el equipo de cantera, la industria alemana de maquinaria y vehículos ha previsto construcciones con un número suficiente de tipos.

En las fábricas alemanas se trata la piedra casi exciusivamente por trituradoras pesadas de martillos (12) (fig. 2). Mientras que anteriormente la trituración de grandes trozos, hasta de $1 \mathrm{~m}^{3}$, se efectuaba con dos trituradoras en serie, las nuevas máquinas rompen el material procedente de la excavadora de cuchara en una sola fase, como puede apreciarse en las curvas granulométricas del gráfico 3 (comparación del proceso de las dos trituradoras de tipo antiguo de martillos con la trituradora moderna de martillos).

El consumo de piedra por día en una fábrica de tipo medio exige un gran rendimiento de la trituradora, por lo que se han seguido perfeccionando las trituradoras de martillos. Se han llevado a cabo las siguientes ampliaciones: diámetro de la circunferencia de golpeo, hasta $2,5 \mathrm{~m}$; peso de los martillos, hasta $80 \mathrm{~kg}$; velocidad periférica, hasta $30-40 \mathrm{~m} / \mathrm{s}$. En los dispositivos de golpeo desarrollados como discos aparecen cuatro martillos en el contorno. Estos discos se convierten en un tambor rotatorio que hace superflua la cesta de parrilla en la entrada. La posibilidad de disponer los martillos en todo el ancho de la parrilla ha sido realizada por Krupp, que construye los discos con cuatro segmentos desplazados (fig. 4) y, por tanto, se aprovecha mejor la superficie de la parrilla inferior. Una trituradora muy robusta de un solo eje es la trituradora Mamut de Hirschmann y Claes, que se ha montado mucho en los últimos años y cuyo modelo mayor consigue 300 toneladas por hora de material preparado a la medida apropiada para molinos. En el mercado se encuentran diferentes trituradoras de dos ejes. El tipo mayor de la nueva trituradora Titán, de la casa MIAG, tiene un paso por hora de 600 toneladas. En este caso surge un problema de transporte difícil de solucionar en relación con la alimentación correspondiente de piedra para poder corresponder con la capacidad de rendimiento de la trituradora (11).

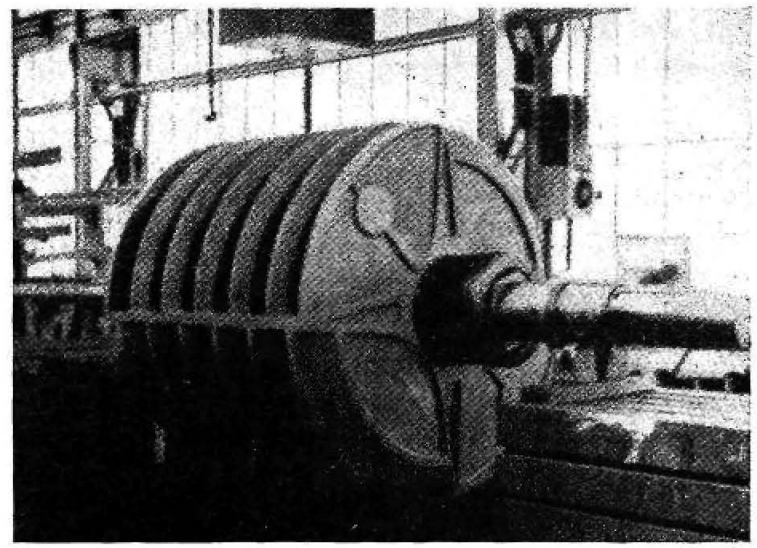

Fig. 4.-Rotor de discos de Ia trituradora de martillos (Krupp).

Fig. 5,-Trituradora de martillos cas (Wedag-Liceneia Seffrey).

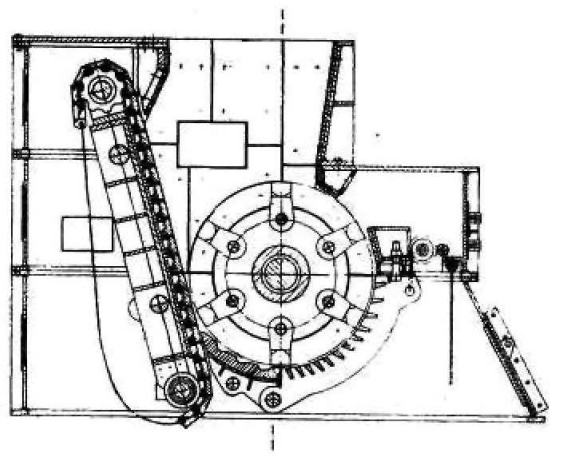

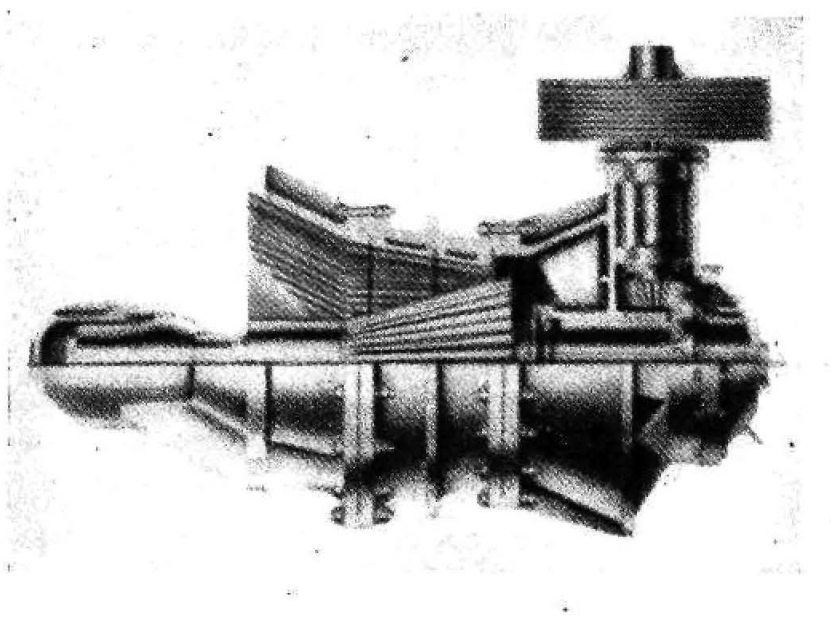

Fig. 6.-Trituradora giratoria de mandibulas (Esch-Werke). 
Para trabajar materiales muy adherentes, la carcasa y la parrilla trituradora se disponen de forma tal que no queden pegadas las partículas de arcilla; con este fin, la casa WEDAG ha dfspuesto una placa trituradora giratoria siguiendo el ejemplo del extranjero (flg. 5).

Las trituradoras de martillo se allmentan por cintas de placas de tipo muy pesado, en posición inclinada, que son necesarias por tratarse de material en grandes trozos. Para poder trabajar sin estas cintas de placas de alimentación, en una de nuestras fábricas se introdujo, de una vez, todo el contenido de un volquete en una trituradora de percuslón de la casa Hazemag. En otras industrias se emplea con este mismo fn la trituradora giratoria grande, que en los Estados Unidos trabaja como pretrituradora. En la República Federal la casa Esch-Werke ha creado con este mismo objeto una trituradora giratorta de mandibulas (flg. 6), cuyo tipo mayor trabaja con $2.000 \mathrm{t} / \mathrm{h}$. Un anillo de arrastre (o transportador) extrae el material toscamente triturado para alimentarlo a una cinta transportadora o a una trituradora de finos dispuesta en el mismo plano (fig. 7).

La trituradora móvil en el frente de explotación presenta la ventaja de poder transportar el material pretriturado en forma continua con un transporte de cinta más económlco hasta la trituradora de fino. La casa Krupp ha desarrollado una trituradora de martillos montada sobre orugas, con un rendimiento de 150 toneladas por hora (flg. 8). Una construcción similar que ha sido equipada con neumáticos por la casa WEDAG (fig. 9) se encuentra trabajando hace años en las fábricas de la Baja Sajonia. El transporte de la piedra hasta la trituradora secundarla se realiza mediante cintas tranportadoras que se desplazan con la trituradora móvil. En rendimientos superiores de la cantera es preciso montar varias trituradoras, dependiendo este procedimiento de la economía y apareciendo delimitado para canteras de tipo medio.

La arcilla se obtiene por medio de excavadoras de cangilones y excavadoras de rueda de cangilones (fig. 10). Una nueva solución se ha empleado en una de nuestras mayores fábricas valiéndose de una excavadora con cuchara de arrastre desarrollada por la casa Menck \& Hambrock (figura 11). La cuchara, con un contenido de $3 \mathrm{~m}^{3}$, cuelga de una pluma de $25 \mathrm{~m}$, dando a esta máquina una capacidad de explotación y carga de 200 toneladas/hora.

La marga blanda y la greda se pueden explotar en las capas superiores sin voladura, usando excavadoras de cuchara con suficiente fuerza de arranque. La greda húmeda en las capas de mayor profundidad se explota con excavadoras de rueda de cangilones o por excavadoras con cinta de cangilones (fig. 12). Debido al elevado rendimiento y al esfuerzo motivado por las piedras de pedernal más o menos grandes que se encuentran en la greda, se necesitan construcciones especia n:ente sólidas. Estas dragas o excavadoras descargan, como mejor solución, sobre transportadores de cinta (13), que llevan el material explotado a la fábrica para el proceso de fabricación. El material muy pegajoso requiere medidas especiales bajo las condiciones rudas del invierno, con el fin de poder mantener limpias las cintas y conservar un funcionamiento perfecto.

\section{Proceso de via húmeda}

La subsiguiente preparación de la pasta del crudo con greda se efectuaba hasta ahora en un gran depósito desleidor, en el que se retenían los trozos de pedernal o trozos duros arrastrados por la greda, al no poderse desleír en el conjunto de la pasta. Las máquinas para hacer la pasta tienen que liberarse en momentos determinados de las piedras. Si resultan muy frecuentes los períodos de limpieza por el elevado contenido de piedras, entonges es ventajosa la desleidora de trabajo contintu desarrollada por la casa F. L. Smidth en los últimos cinco años (flgura 13). En tambores de $3 \mathrm{~m}$ de dímetro y $6 \mathrm{~m}$ de longitud se pueden desleir por hora de 200 a 300 toneladas de greaa con $70 \% \mathrm{R}$. en $0,09 \mathrm{~mm}$ (las piedras se lavan y se expulsan continuamente). Este tambor, desarrollado en principto sólo para greda con elevado contenldo de piedra, se emplea ahora también para greda pura (sin pledras) y arcllla, obteniéndose, en estas condiciones, un rendimiento de 500 toneladas por hora. Dadas las propiedades, la pasta tiene que pasar todavia por un molino de refino para moler las partículas groseras. El consumo especifico de trabajo para el desleimiento y la molienda flna se considera de $\theta$ a $10 \mathrm{kWh} / \mathrm{t}$ de material seco.

La greda que contiene pocas piedras (flint) también se deslie en la trituradora de percusión de la casa Hazemag (flg. 14). Las piedras gruesas se separan por un tamiz y la pasta en bruto se somete a nuevo-desleimiento. El trabajo principal lo efectúa la trituradora de percusión; una de estas máquinas puede ofrecer un rendimlento de hasta $400 \mathrm{t} / \mathrm{hora}$. 


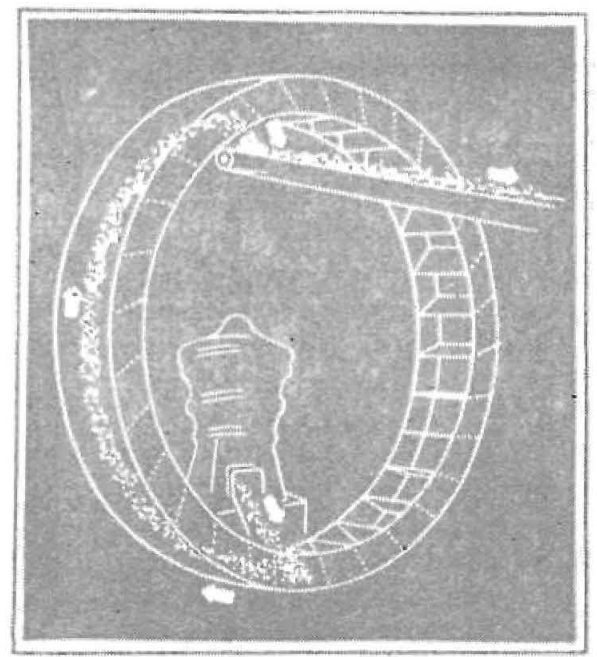

Fig. 7.-Trituradora giratoria de mandibulas con anilo transportador (Esch-Werke).

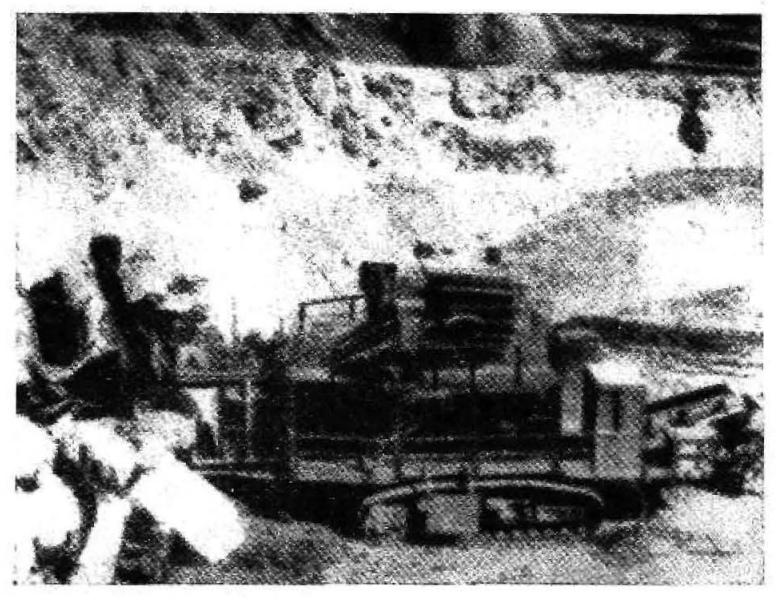

Fig. 8.-Trituradora de martillos montada sobre orugas (Krupp).

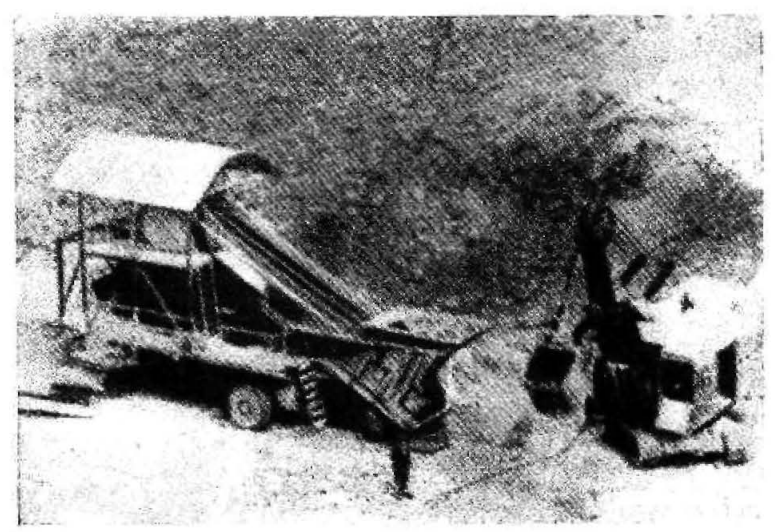

Fig. 9.-Trituradora móvil sobre neumáticos (WEDAG).

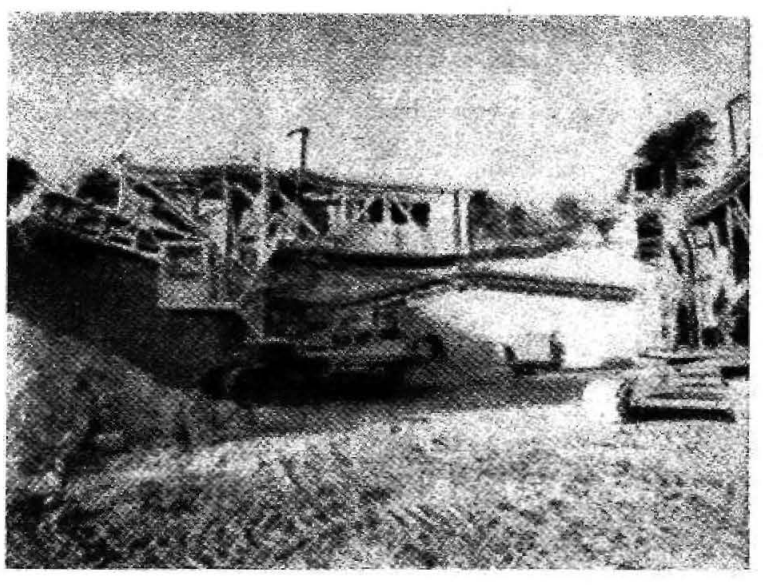

Fig. 10.-Exeavadora de rueda de eangilones (Orenstein \& Koppel).

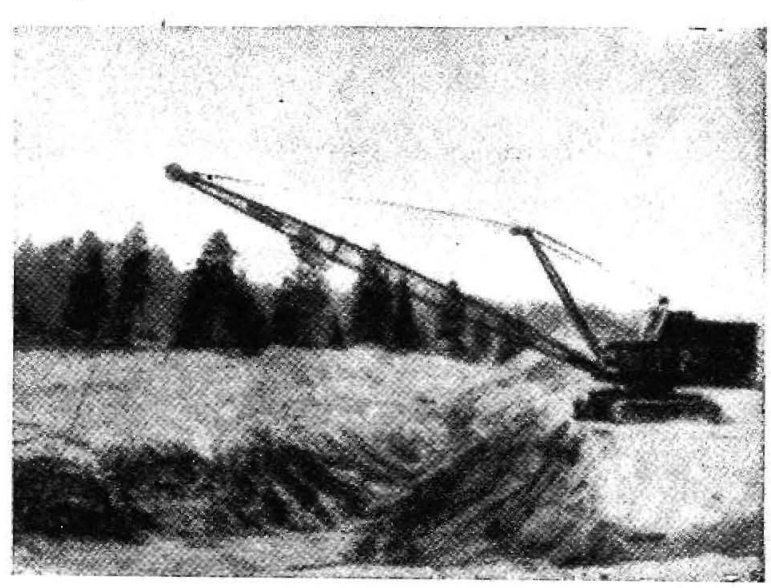

Fig. 11.-Excavadora con euchara de arrastre para areilla (Menck \& Hambroek).

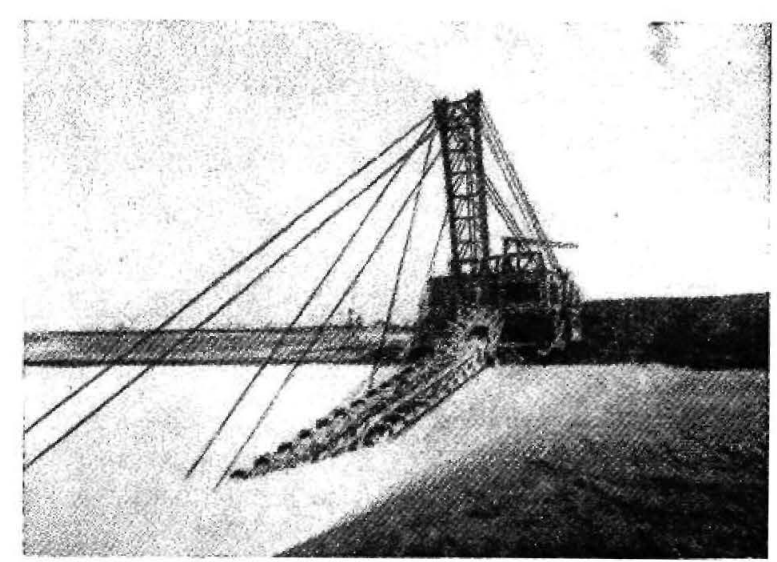

Fig. 12.-Excavadora de rosario para greda (Buckau-Wolf). 


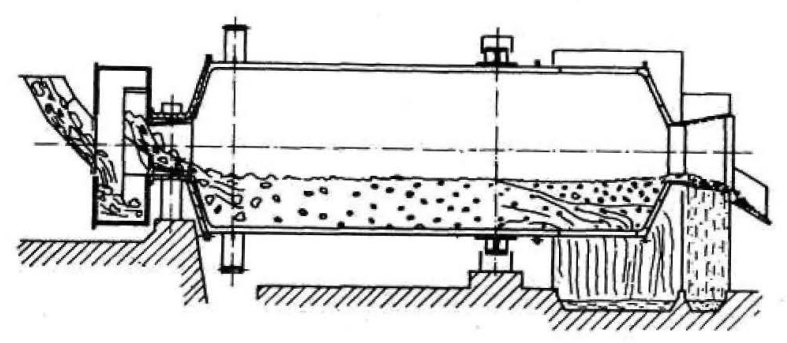

Fig. 13.-Tambor para pasta (F. I. Smidth).

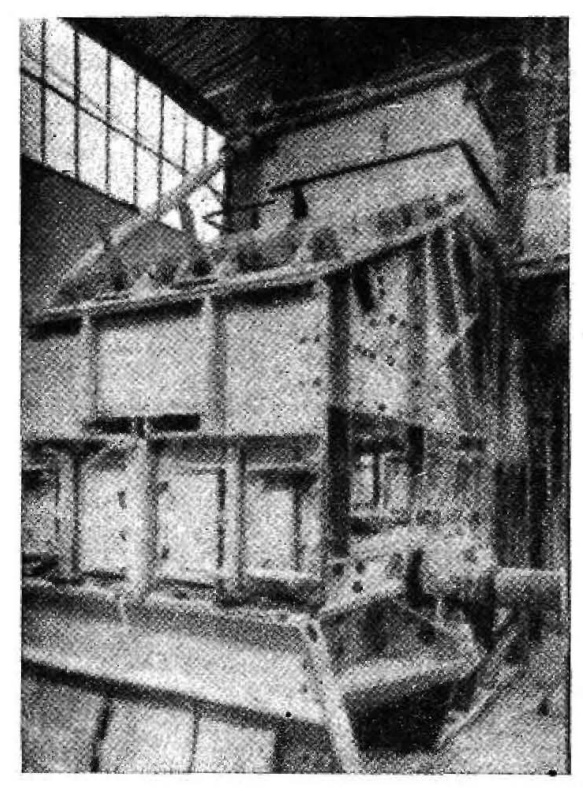

Fig. 14.-Trituradora de pereusión con humedad (Hazemag).
A continuación de cada trituradora de percusión se expulsan los residuos de guijarro en una o dos desleidoras.

La molienda húmeda de la caliza (14) no ofrece casi ningún nuevo desarrollo; se sigue realizando en molinos preparadores y molinos de refino o en molinos compuestos con una fuerza de arrastre de hasta $2.000 \mathrm{~kW}$. En el caso de calizas duras aparece un residuo desfavorablemente elevado en el tamiz de $0,2 \mathrm{~mm}$ (DIN 4188). Para separar las chinas de caliza de la pasta acabada son inadecuados los tamices húmedos; el tamizado intermedio antes de la molienda flna, que podria eliminar los trocitos mayores de caliza, aumenta el contenido de agua en la pasta. Una solución de este problema podría conseguirse con los molinos de barras acreditados en el tratamiento de minerales, que deberían ser aprovechados en la industria del cemento. En USA ya se ha seguido esta solución con éxito (15).

Las instalaciones de molienda húmeda no deben trabajar en el futuro durante los domingos. Las materias primas con un elevado contenido de humedad en cantera, solamente se pueden distribuir en el hangar con el puente-grúa $\mathrm{y}$, por tanto, siempre se precisa personal de servicio. En consecuencia, las instalaciones para la preparación en vía húmeda tendrán que disponerse como el trabajo de cantera, para un servicio de cinco días, con el fin de conseguir la cantidad de pasta necesaria para los siete días de la semana.

Los silos de pasta deben poder contener una cantidad de pasta preparada para un funcionamiento de tres días, con objeto de poder cubrir las necesidades de la producción para el siguiente día de trabajo. Cuando las materias primas varían considerablemente, la preparación de la pasta tenđrá que llevarse a cabo mediante el procedimiento de corrección. Esto requiere o exige un número mayor de silos para las pastas correspondientes valoradas, que tienen que aparecer por separado en relación con el contenido de cal, arcilla y ácido silícico.

Las instalaciones son costosas y complicadas en comparación con la homogeneización continua con sólo tres recipientes (fig. 15), los que en relación con la producción tienen que tener una capacidad unitaria de 3.000 a $5.000 \mathrm{~m}^{3}$.
Fig. 15.-Instalación de homogeneización para pasta (F, L. Smidth)-del departamento de molinos-al horno. 
Mediante tomamuestras que trabajan en forma continua se realiza la valoración a la salida del molino, corrigiendo la composiclón de la mezcla del crudo. Procedente del mollno se reparte la pasta en toda ia superficie del primer recipiente de pasta por un mecanismo removedor, equipado con homogeneización neumática. Cuando este recipiente se completa tiene lugar un rápido equilibrio. La sigulente homogeneización se efectúa en el recipiente siguiente, que también debe estar lleno, mientras que el horno se alimenta por el tercer recipiente. En el tiempo que se para la molienda se puede vaciar el tercer recipiente. Para diferentes calldades de clinker se deben prever, en casos determinados, depósitos de reserva.

Los hornos rotatorios de via húmeda permiten apreciar-más que en otros casos-la tendencla a mayores unidades en las máquinas, de tal forma que, en la actualidad, los hornos de 500 toneladas pertenecen ya a los tipos pequeños. La casa Miag construye hornos, con precalentadores por separado, calcinator); la casa Krupp, con el concentrator; Polysius, con el seccator, y la casa Vickers, con el deseccator. Un horno de 750 a 800 toneladas se construye con una longitud de $90 \mathrm{~m}$ y con un diámetro de $4,20 \mathrm{~m}$, con un ensanche de $4,5 \mathrm{~m} \varnothing$ en el lado de la carga. El concentator (flg. 16) de un horno tan grande tiene una cesta de $5 \mathrm{~m}$ de dímetro y un ancho de $4 \mathrm{~m}$. La construcción de este gran tambor de parrilla, que en una vuelta o giro aparece expuesto a los gases calientes y a los gases más fríos de salida, requiere una experiencia especial. Aumentando las dimensiones de la cesta, resulta cada vez mús difícil conducir unlformemente los gases de la sallda del horno por el precalentador. La distinta dilatación de la carcasa y la cesta permite el libre paso de los gases calientes alrededor de la cesta, de forma que éstos pasan sin aprovechamiento al ventilador de salida. Por este motivo se prefleren, para gran paso de material, los hornos rotatorios de vía húmeda largos; éstos presentan la ventaja, frente a los hornos equipados con precalentadores independientes, de que entre el horno y el precalentador siempre penetra afre falso (16) que desvirtúa la elevada temperatura de los gases del horno. Hace ya siete afios, la $\mathbf{S}$. A. Ciments d'Obourg hizo el paso hacla unidades mayores, construyendo un horno de 1.200 toneladas de 4 o 4,50 metros de diámetro y una longitud de $165 \mathrm{~m}$ (7). La instalación ha sido ampliada posterlormente con un horno de $5 \mathrm{~m}$. El horno ha sido suministrado por la casa francesa Fives-Lille, la cual, en Portugal, ha montado hornos todavia mayores. En Rusia están construyendo dos hornos de $175 \mathrm{~m}$ de longitud que tienen $\operatorname{los}$ siguientes diámetros: $5,7 \mathrm{~m}$, en la zona de sinterización; $5,2 \mathrm{~m}$, en la zona de calcinación, y $6,2 \mathrm{~m}$, en la zona de secado. Cada uno de estos hornos deberá tener una producción de 2.750 toneladas de clinker por dia (4), correspondiendo con una carga específica del horno de $700 \mathrm{~kg} / \mathrm{m}^{2} /$ día. Estas son las perspectivas en la construcción de hornos rotatorios que por el momento sobrepasan nuestras ideas. Frente a nuestros tipos de 800 a 900 toneladas por día surge la duda de si trabajan más favorablemente desde el punto de vista térmico, según los conocimientos que tenemos hasta la fecha (18). Seguramente Ios medios de inversión no son considerables calculados en relación con la capacidad de rendimiento por tonelada por año, resultando para los gastos de funcionamiento también un divisor favorable.

Al crecer la longitud de los hornos crece también el número de anillos de rodadura, los cuales tienen que encontrarse bien alineados estre si (19), si se quiere mantener reducido el desgaste de los anillos de rodadura frente al de los rodillos donde se apoyan, interesándose, por otra parte, en mantener reducido el consumo de energia para el accionamiento. Ahora, al fin, se construyen grandes hornos rotatorlos sobre rodillos de compresión (fig. 17) que absorben el desplazamlento o deformación longitudinal del horno (19), de forma que los rodillos de apoyo se pueden orientar en paralelo con Ios anillos de rodadura.

\section{Proceso de via seca}

El desarrollo de la maquínaria para la vía seca se ha tratado anteriormente con más detalle. Para la explotación de la cantera y para la instalación de trituración rige lo anteriormente indicado. En el pasado año, $\mathbf{E}$. Voos informó sobre las modernas instalactones de homogeneizaclón de crudo (20), con lo que en el proceso de vía seca se consigue una mezcla del crudo tan buena como en la via húmeda. Esto hace que el proceso de vía seca pueda emplearse, no solamente para matertales que van bien por su reducido contenido de agua, sino también para materiales con mayor humedad, cuando el consumo superior de calor en el secado pueda cubrirse o contrarrestarse con el calor expulsado y recuperado del horno. Los sistemas de hornos con precalentadores en suspensión gaseosa ofrecen todavia un calor residual en los gases de escape superior a $150 \mathrm{kcal} / \mathrm{kg}$ de clínker. 


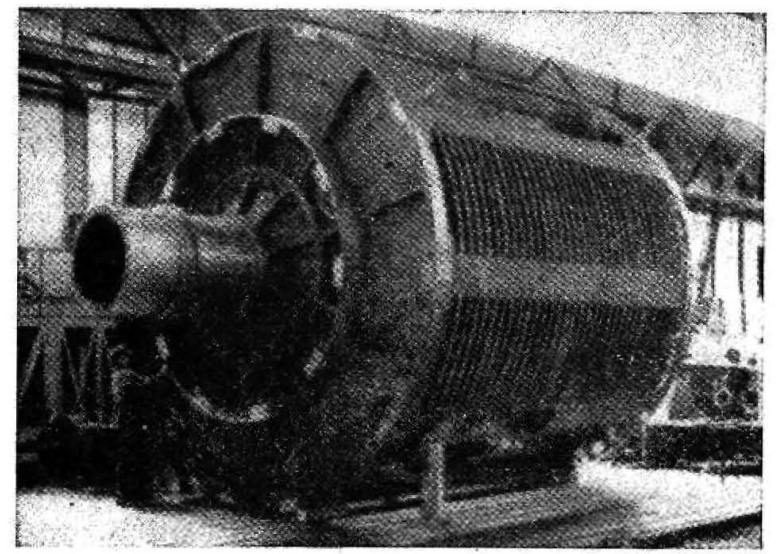

Fig. 16.-Cuerpo de parrilla giratoria de un concentrator (Krupp)

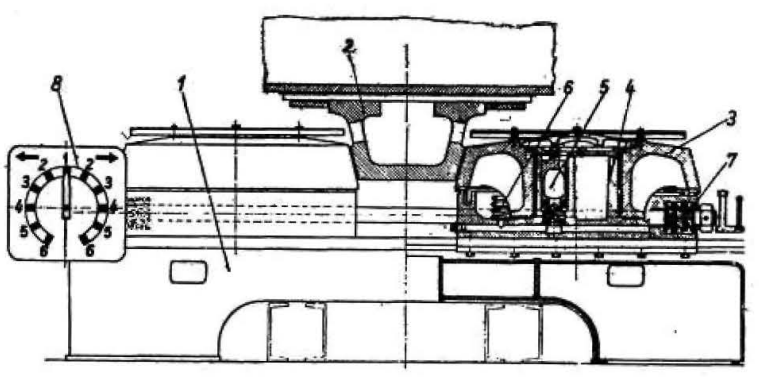

Fig. 17.-Apoyo de compresión para hornos rotatorios, que absorbe el empuje longitudinal (MIAG).

1. Caballete de apoyo de construcción soldada. -2 . Anillo de rodadura. - 3. Rodillo de compresión.-4. Carcasa con muñón.tín de refrigeración. - 7 . Muelle para absorber el empuje elástico. 8. Dispositivo indicador de la amplitud y sentido del desplazamiento.

Fig. 18.-Molino de rodi-

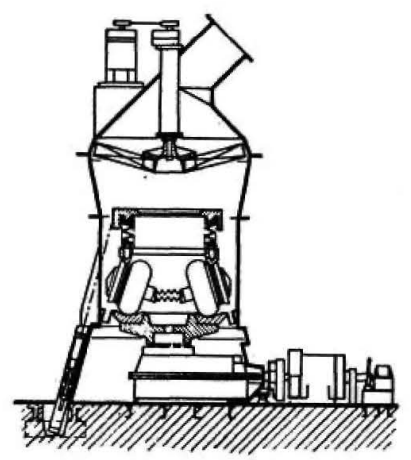

Los gases del enfriador Fuller-que se emplea tanto en el horno Lepol como en el procedimiento de suspensión gaseosacontienen, con una temperatura de 200 a $250^{\circ} \mathrm{C}$, de 60 a $80 \mathrm{kcal} / \mathrm{kg}$ de clínker $(21$ y 22). Cuando se desea aprovechar estas cantidades de calor relativamente elevadas a bajas temperaturas, deben aparecer especialmente previstos los dispositivos de preparación del crudo.

En los últimos años se han construído en gran escala, como elementos secadores y de molienda simultánea, los molinos en circuito cerrado con elevador de cangilones (23). Esta disposición, presentada en el mercado por primera vez por la casa Polysius, se construye actualmente por todas las casas importantes. Los molinos con $3,6 \mathrm{~m}$ de diámetro y la longitud correspondiente, que molturan 100 toneladas hora de material, son ya muy frecuentes. Según la aptitud a la molienda de las materias primas, el consumo específico de energía de 10 a $12 \mathrm{kWh} / \mathrm{t}$ se corresponde con $10 \%$ de residuo sobre $0,09 \mathrm{~mm}$ y $0,5 \%$ sobre $0,2 \mathrm{~mm}$. En el caso de un contenido reducido de humedad (hasta un $3,5 \%$ ) se puede secar con este sistema de molienda aprovechando sólo el aire caliente de las salidas del enfriador Fuller sin calentamiento especial. Con los gases del precalentador de suspensión gaseosa puede trabajarse un material hasta con un contenido de humedad de $4,5 \%$. Cuando surgen porcentajes de humedad superiores se tienen que calentar los gases o el aire, incluso en el caso de disponer de mayores cantidades de gases recuperados, que ya no se pueden emplear en el molino de circuito cerrado con elevador de cangilones (22).

Para el más amplio aprovechamiento del calor recuperado a baja temperatura se tiene que alargar el tiempo de paso del calor, lo que realmente requiere la disposición de secadores de tambor a velocidad más reducida, los que, en la actualidad, aparecen en disposición hasta con las mayores medidas.

Si aumentamos durante el secado la superficie del material, el intercambio de calor puede tener lugar en un plazo más breve.

Esta solución (23) ha sido introducida en los Estados Unidos por G. Claes y Hischmann, disponiendo trituradoras de martillos delante de los viejos molinos tubulares, por las que se pasaba aire caliente. 
A la vez se calientan los separadores del circuito cerrado, para secar completamente el material en forma granular antes de su entrada en el molino tubular. Este principio, empleado también por otras fábricas de maquinaria en forma variada, ha sido aplicado con éxito en un molino moderno de circulto cerrado con elevador de cangilones, en el que se ha secado, con gases del precalentador que salen del horno a $300^{\circ} \mathrm{C}$, crudo con una humedad del $4,5 \%$. Este molino que se encuentra en la zona de Beckun, con sólo un diámetro de $2,6 \mathrm{~m}$, tíene la longitud correspondiente para una producción de $75 \mathrm{t} / \mathrm{h}$, resultando al mismo tiempo un consumo total de energía de unos $10 \mathrm{kWh} / \mathrm{t}$. Sería interesante comprobar hasta qué contenido de agua se puede trabajar con esta instalación sin tener que emplear un recalentamiento.

Un nuevo desarrollo se presenta con los molinos verticales de rulos comprimídos por muelles. Hace aproximadamente diez años, $M$. Berz creó un nuevo molino yertícal con rodillos, actualmente mejorado hasta tal punto que puede competir con ei mejor molino de clrculto cerrado con elevador de cangilones (fig. 18). En Neubeckum trabaja desde hace medio año un molino Berz con un paso de material de 70 a $80 \mathrm{t} / \mathrm{h}$. Con $10 \% \mathrm{R}$ en $0,09 \mathrm{~mm}$ ó $1,5 \% \mathrm{R}$ en $0,02 \mathrm{~mm}$, resulta un consumo de energía de $11,5 \mathrm{kWh} / \mathrm{t}$ para todos los motores, incluyendo el ventilador del filtro. El molino con la soplante consume $10,3 \mathrm{kWh} / \mathrm{t}$; de éstos, solamente $5,5 \mathrm{kWh} / \mathrm{t}$ se dedican al trabajo de molienda en sí. En el molino vertical con rodillos, tres rodillos de diámetro relativamente grande se desplazan sobre la pista accionada desde abajo. Cada uno de los rodillos de molienda marcha bajo un anillo común de compresión, el cual transmite la presión de molienda sobre la superflcie de la plsta. Con este molino ha aparecido en el mercado una máquina de elevado rendimiento, que destaca por su tranquilidad en el funclonamiento y por su reducido desgaste.

De la colaboración con Berz se ha creado en la fábrica Barbarossa un gran molino vertical con rodillos que presenta una variación, ya que los rodillos dé molienda están apoyados por pesados cojinetes de rodillos en una pieza de compresión, por la cual se transmite la compresión por un anlillo de presión a los rodillos (flg. 19). Esta construcción debe reducir el desgaste de la superflcie de rodadura en el anlllo de compresión. La fábrica Barbarossa prepara el suministro de este tipo de construcción para un paso de material de 60 a 65 t/hora. Estos nuevos molinos han dado tamblén nuevo impulso a los constructores de Loesche, cuyo mayor modelo hasta ahora (LM 16) presenta un rendimiento de $30 \mathrm{t} /$ hora. La casa Loesche, que fue la fábrica alemana que desarrolló el primer molino útil por compresión de muelle, y que se encuentra en funcionamiento en la industria del cemento para la molienda de carbón y materias primas, tiene además un moltno, tipo LM 20, como modelo más grande y está ya en marcha en una fábrica italiana de cemento (figura 20). Este molino tiene un rendimtento de 50 a 55 t/hora con un consumo especiflco de energía de solamente $10,2 \mathrm{kWh} / \mathrm{t}$ para mollno y soplante conjuntos. Loesche hace trabajar su sistema de mollno directamente sobre un filtro eléctrico, que descarga al exterior el aire soporte cargado con $850 \mathrm{~g} / \mathrm{m}^{3}$. En el proceso de molienda y secado, este molino trabaja con material con un contenido de humedad de hasta un $18 \%$; esto resulta posible con un hogar Loma, que recalienta, de una manera muy sencllla, el gas reeuperado del horno rotatorio o del enfriador. Las dos fábricas últimamente citadas han desarrollado otros tipos de molinos para una circulación de material de 80 a 90 t/hora.

El molino de rodillos trabaja con una carga circulante de material muy elevada, por cuyo motivo puede trabajar con un material muy húmedo, ofreclendo, al mismo tiempo, nuevas posibilidades para el aprovechamlento del reducido calor recuperado del horno. Para el trabajo real de trituración se invierte mucha menos energia en comparación con la que se necesita en los molinos de bolas, con lo que queda compensado el consumo elevado del circuito neumático y de la separación en el molino. Los resultados obtenidos hasta ahora con este mollno prometen mucho y ocupan un espaclo reducido, ya que no tiene más accesorios que la soplante. Con esto se consiguen Instalaciones de mollenda de mucho rendimiento para materiales blandos $\mathrm{y}$ de dureza media con un contenido elevado de agua, gran seguridad de functonamlento y buen aprovechamiento térmico, con un gasto reducido de inversión. Por su simple construcción y el reducido accesorio de máquínas resulta muy simple la automatización de la instalación, de forma que éstas pueden marchar sin personal durante el domingo y durante la noche.

El desarrollo indicado por $E$. Voos para la homogeneización de crudo ha continuado. Entretanto, se han montado instalaclones que trabajan tanto por el procedimlento de corrección como por el sistema de instalaciones de homogeneización' en silos de gran capacidad.

Los hornos rotatorios de vfa seca merecen una atención especial en la República Federal por su reducido consumo de combustíble. La parte técnico-económica ya se ha tratado ampliamente.

Un buen horno Lepol consume aproximadamente $800 \mathrm{kcal}$ y de 10 a $12 \mathrm{kWh} / \mathrm{t}$ de clínker. El aire saliente del enfriador permite una recuperación de 60 a 80 kcal (22). 

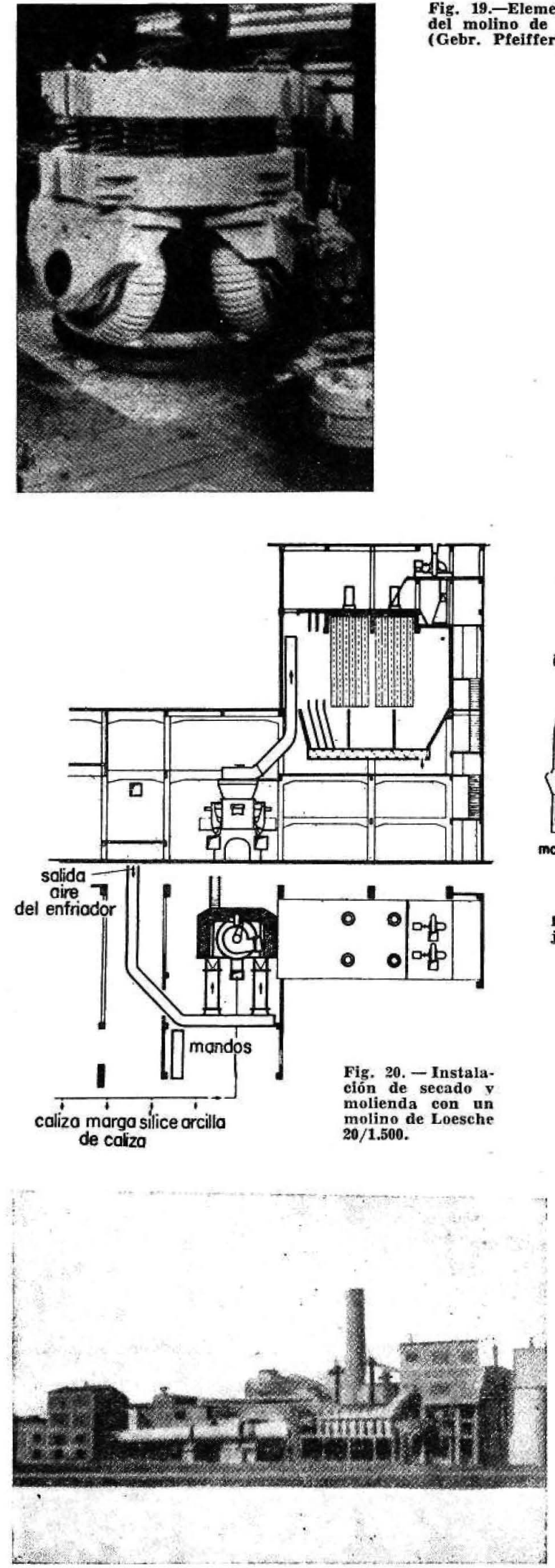

Fig. 21.-Horno Lepol con una producción de 1.000 t/dia (Polysius).
Fig. 19.-Elemento de molienda
del molino de rodillos MPS 200 (Gebr. Pfeiffer).

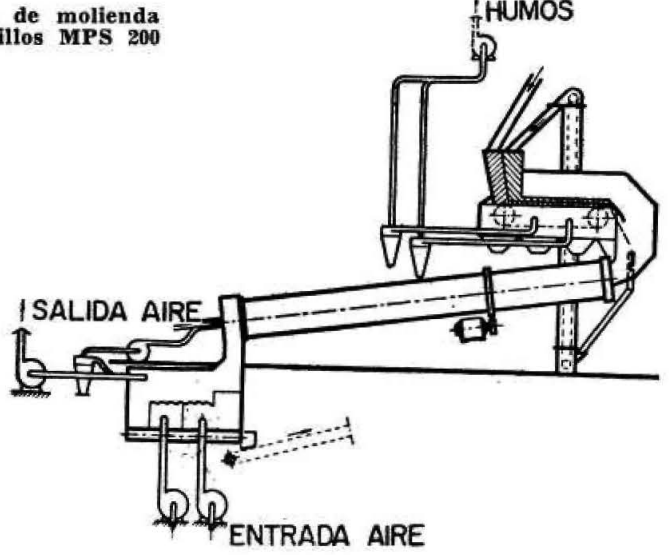

Fig. 22.- Horno rotatorio con precalentador en dos fa ses (MIAG).

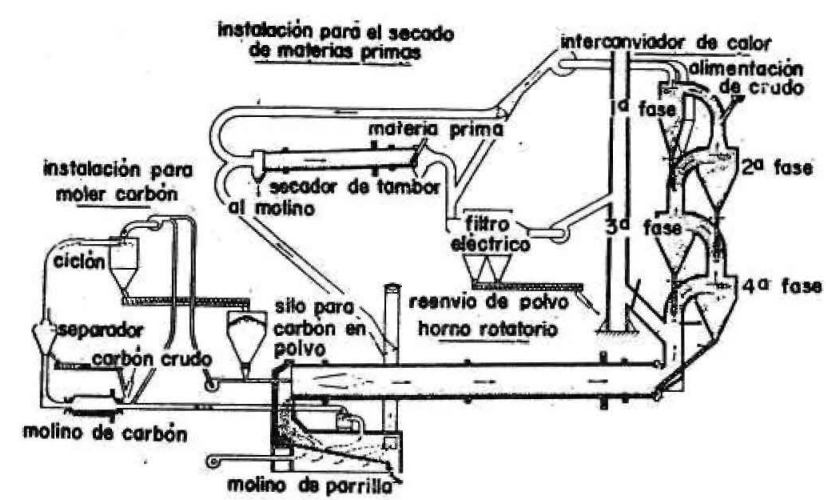

Fig. 23.- Horno rotatorio Humboldt con intercambiador de ealor, junto con el secado de crudo $y$ de carbón.

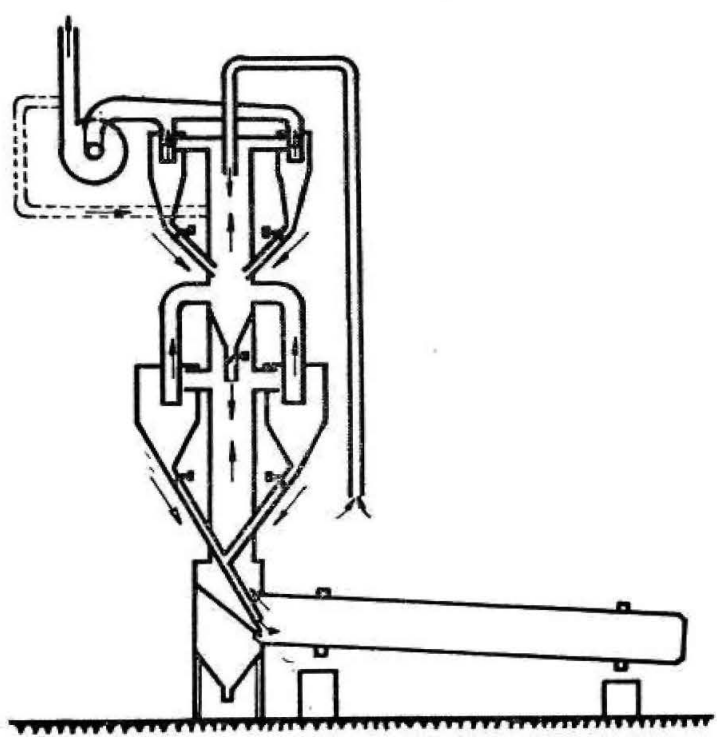

Fig. 24,-Precalentador vertical de torbellino (Poiysius). 
Se encuentran en funcionamiento hornos Lepol con una capacidad de $\mathbf{1 . 0 0 0}$ toneladas (figura 21), esperándose alcanzar una capacidad de $1.200 \mathrm{t}$ /día en las nuevas construcciones. El poder conseguir tipos más grandes de hornos dependerá de la parrilla Lepol. Las parrillas más anchas $(4 \mathrm{~m})$ y largas son más serisibles a los fallos mecánicos en comparación con las parrillas pequeñas. Los hornos Lepol son Ios más empleados actualmente, y la mayoría de los hornos de la República Federal son hornos Lepol. El precalentador de parrilla encontró una nueva solución en la casa MIAG, que ha desarrollado una parrilla (fig. 22) que trata el material en dos etapas. Esta parrilla no ha sido empleada todavía para la producción de cemento, pero presenta ventajas para la cocción de material en trozos pequeños. La casa Fellner \& Ziegler efectúa también un desarrollo en este sentido.

El horno Humboldt de suspensión gaseosa ha surgido en los últimos años como una gran unidad para una producción de 700 a 800 toneladas. El consumo de combustible de las pequeñas instalaciones de este tipo es de 4 a $5 \%$ mayor en comparación con el consumo del horno Lepol (22); en los modelos mayores se debería disminuir esta diferencia. El consumo específico de energía de los nuevos modelos se ha reducido hasta 14 ó $16 \mathrm{kWh} / \mathrm{t}$ de clínker. Del aire del enfriador y de la salida de gases del horno se pueden recuperar, en total, más de $200 \mathrm{kcal}$ por $\mathrm{kg}$ de clínker. Al poder conseguir este aprovechamiento, para el que aparecen nuevas posibilidades cuando se emplean materias primas de mayor humedad en el proceso de vía seca, se consigue con este sistema un rendimiento térmico considerable. Se encuentra en período de construcción una instalación con un secador de tambor para una producción de 700 a 800 t/día (fig. 23). Próximamente se pondrá en marcha un horno de las mismas dimensiones en conexión con un molino de circuito cerrado con elevador de cangilones. El progresivo desarrollo de Humboldt, realizado muy cuidadosamente, hace prever un éxito de estas instalaciones tan rotundo que no aparecerá ningún obstáculo en el paso siguiente para conseguir una producción de $1.000 \mathrm{t} /$ día. Los constructores opinan que predominarán los hornos hasta de una producción de $1.500 \mathrm{t} /$ día. Por parte del horno rotatorio y por el enfriador no se aprecian dificultades, pero falta todavía la experiencia en relación con el comportamiento del crudo en el intercambio de calor en los ciclones de grandes dimensiones.

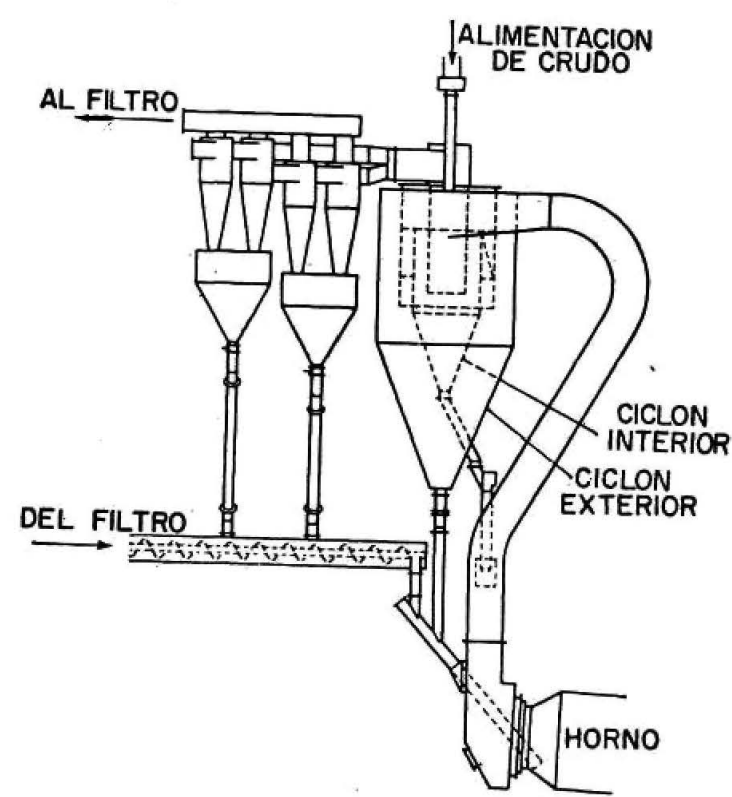

Fig. 25,-Intercambiador de calor (F. L. Smidth).

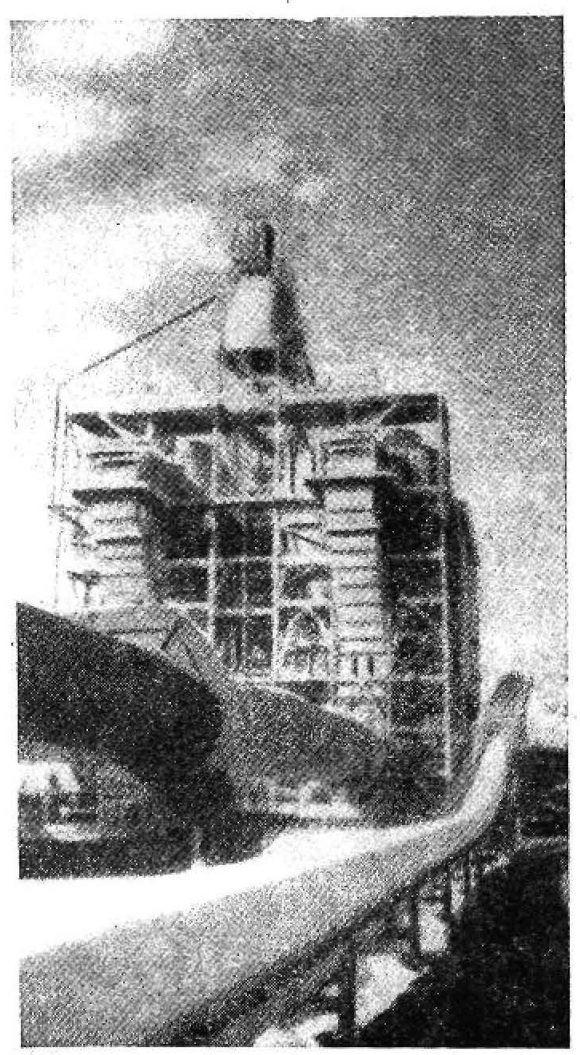

Fig. 26.-Horno rotatorio con intercambiador de calor (r. L. Smidih) 
Se observa que podrán efectuarse mejoras en los precalentadores de suspensión gaseosa, ya que tanto Polyslus como F. L. Smidth han desarrollado un precalentador; y lo mismo Krupp, en relación con un precalentador para crudos con un intercamblo de calor en fases. Polysius emplea un sistema abreviado de intercambio de calor: dos ciclones trabajan en paraielo en un canal con torbellino (fig. 24), en el que se realiza el intercambio de calor. La primera instalación, con una producción diaria de 200 toneladas, trabaja satisfactoriamente durante un año después de haber solventado las diffcultades iniciales y refleja un consumo térmico en correspondencia con el paso redueido de materlal. La casa F. L. Smidth tiene en functonamiento en el extranjerò un sistema de dos fases, cuya forma de trabajo aparece representada en la flgura 25. Los gases del horno transmiten su calor en el precalentador-que está formado por un ciclón exterior y uno interioral crudo alimentado por el conducto del ciclón interior. Tamblén están previstos pequeños ciclones para la captación de polvo. La figura 26 muestra una instalación que se encuentra en funcionamiento en el extranjero, sin conocer hasta el momento sus resultados. La casa Krupp ha construído un precalentador que no se desarrolla en altura. Su disposiclón se puede apreciar en la figura 27. Se halla en periodo de construcción una instalación para una producción de $700 \mathrm{t} /$ día, de forma que pronto se dispondrá de los resultados de su funclonamiento.

Todavia queda por comprobar si F. L. Smidth suministra también su horno largo para la vía seca, con un consumo de $1.050 \mathrm{kcal} / \mathrm{kg}$ de clinker y hasta $950 \mathrm{kcal}$ en condiclones favorables, alimentando crudo seco. Esto es aceptable cuando se pueda aprovechar el calor saliente del horno para el secado del material, considerando, al mismo tiempo, que el consumo específico de energía de este horno largo es de unos cuantos $\mathrm{kWh} / \mathrm{t}$ menos que el de los homos con precalentadores.

Un problema de actualidad en USA y que en Europa tiene todavía poca importancia, es la reducción de los álcalis en el clínker (24). Los compuestos alcalinos acumulados en el circuito del horno (25) pueden extraerse del proceso con el sistema del horno Lepol a través del polvo sedimentado en el captador de polvo intermedilo. Cuando no existe otra posible aplicaclón, este polvo enriquecido en álcalis hay que eliminarlo del proceso; representa del 2 al $3 \%$ de la produeción de clínker y origina una reducida pérdida de material para el horno. En el horno con suspensión gaseosa se tiene la posibilidad de absorber los gases del horno antes de su entrada en el primer ciclón separando el polvo flno, enriquecido con álcalis, mediante un captador especial de polvo. Este procedimiento representa un gasto y origina pérdida de calor, que podria considerarse aceptable si, por otra parte, se puede compensar con una marcha más uniforme del horno, con una producción superlor $y$ con un consumo térmico total más reducido.

Los hornos largos, que en el proceso de vía húmeda no usaban hasta ahora captador de polvo, tienen un retorno tan considerable de polvo, si estản equipados con filtros eléctricos-al tgual que los hornos de via seca-, que pueden perturbar considerablemente las condiciones de funcionamiento de los precalentadores. Por este motivo la casa F. L. Smidth ha previsto un dispositivo especial, que recoge el polvo separado por el filtro eléctrico en un silo, que después se alimenta uniformemente en la zona de precalentamiento, con lo que se consigue una mayor uniformidad en el funcionamiento del horno.

Un procedimiento completamente nuevo para la cocción del clínker, que consiste en cocer el crudo en la zona o capa de torbellino, ha sido inventado por el americano Pycel. La casa Fuller ha montado una instalación de ensayo cuya marcha puede apreciarse en el esquema de este principio (flgura 29). La idea de la posibilidad de elaborar un clinker aprovechable se basa en lo sigulente: una cantidad determinada de clínker acabado, de granulometria flna, se introduce como semilla en el Iecho con torbellino, con el fin de que las particulas del crudo en su fase de sinterlzación queden adheridas a la semilla para formar gránulos gruesos de clínker. La Instalación de ensayo trabaja en escala semi-industrial, apareciendo, por el momento, con un rendimiento térmico por debajo de lo esperado, pero suministrando un clínker perfecto en calldad.

No debemos olvidar las parrillas de cinta para la cocción de clínker de Lurgi, sobre las que ha informado R. Rohrbach (22) en el coloquio de la Asociación Alemana de Cementeros. En la fábrica de Dotternhausen, la capacidad de rendimiento de las cintas se ha aumentado considerablemente con perfecclonamientos en el procedimiento; la producción por dia se ha aumentado desde 300 toneladas hasta 500 por unidad de maquinaria. Con una cuidadosa preparación del coque se consigue reduelr el consumo térmico total de hasta $1.050 \mathrm{kcal} / \mathrm{kg}$ de clínker. Los gases de sallda se aprovechan en la instalación de secado y molienda, mientras que se mantienen a una temperatura superior a $\operatorname{los} 400^{\circ} \mathrm{C}$, con lo que se recuperan $80 \mathrm{kcal} / \mathrm{kg}$ de clínker. 


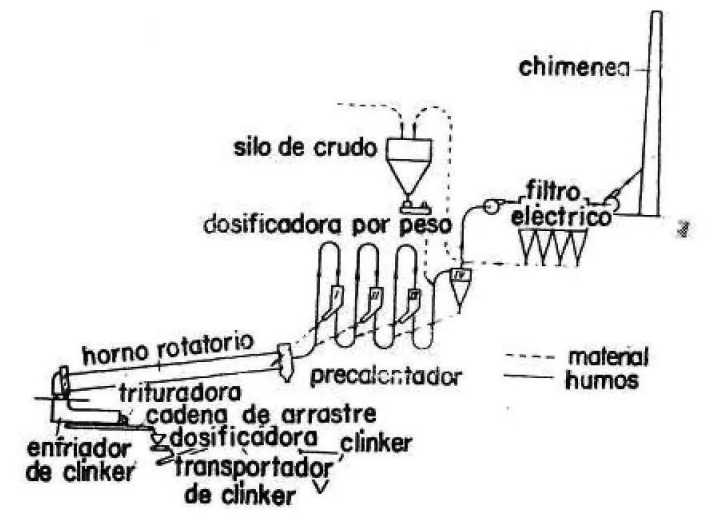

Fig. 27.-Intereambiador de calor (Krupp).

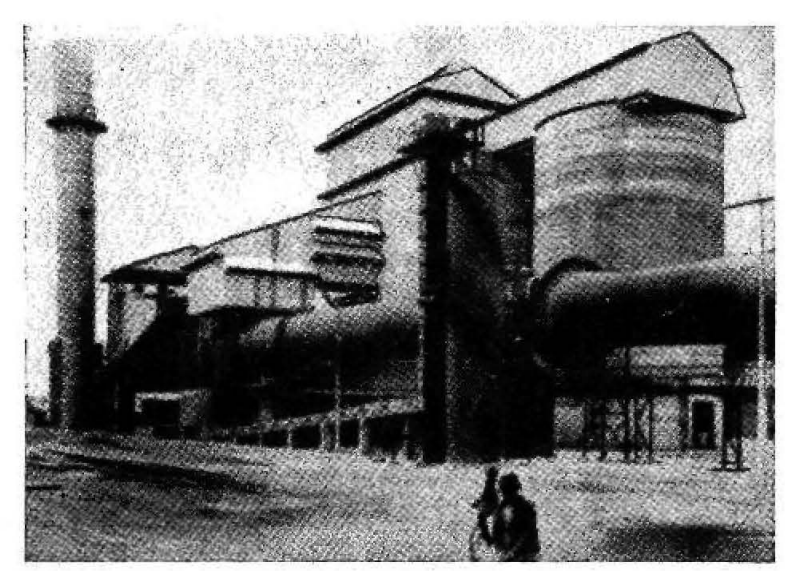

Fig. 28.-Horno rotatorio vía húmeda con recuperación de polvo en el centro del tubo (F. L. Smidth).

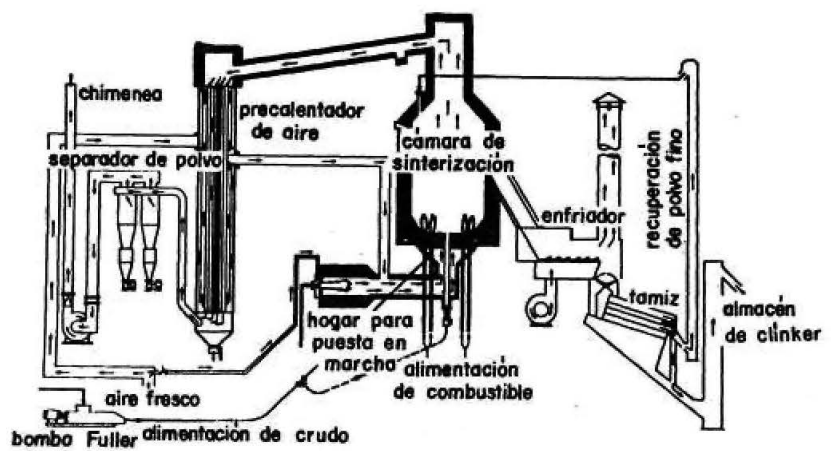

Fig. 29.-Procedimiento de cocción de cemento de Pycel (Fuller).

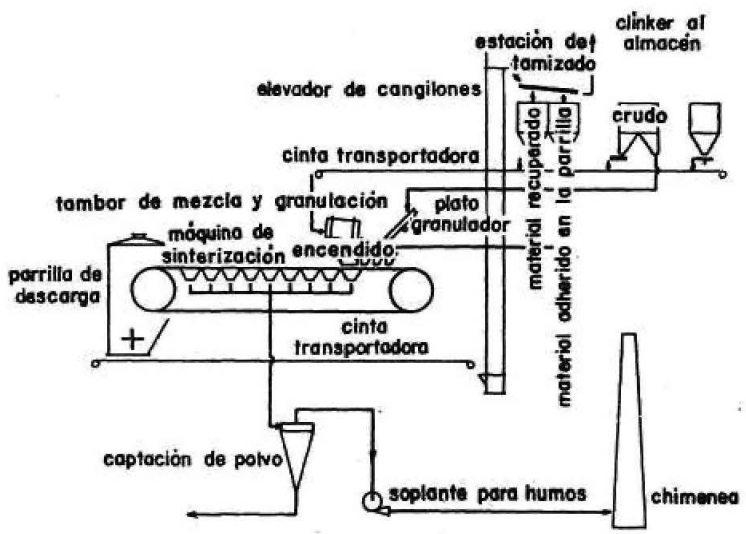

Fig. 30.-Parrilla de sinterización trabajando en doble capa (Lurgi).

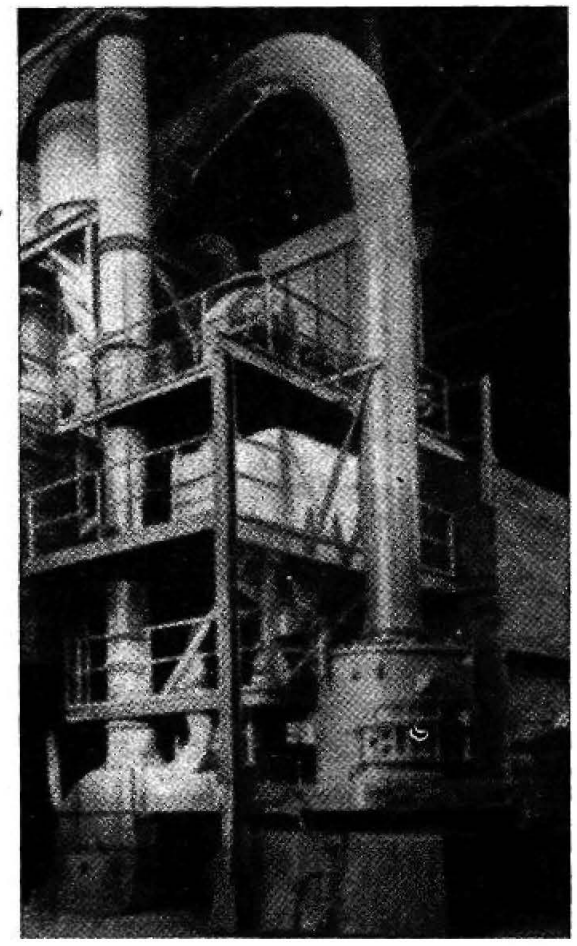

Fig. 31.-Instalación central de molienda para carbón (Cl. Peters).

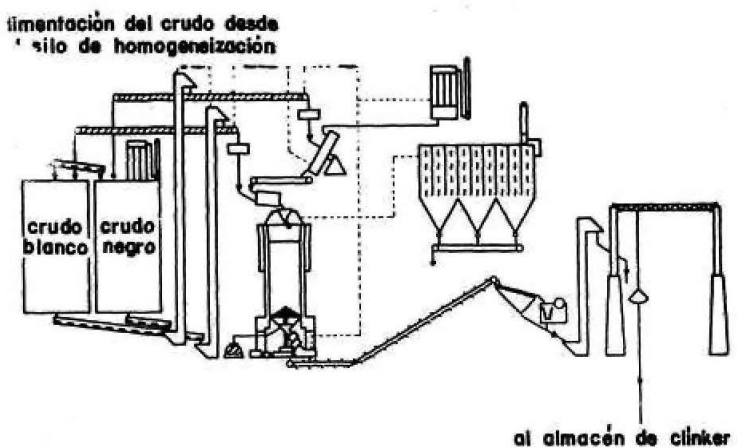

Fig. 32.-Instalación de horno vertical por el procedimiento de Spohn de crudo negro (Loesche). 
En el nuevo procedimiento en dos fases (fig. 30), el materlal recuperado se mezcla con una cantidad de combustible menor en comparación con la mezcla del crudo, empleándose, después de una granulación por separado, como capa superior sobre los gránulos frescos y capa superlor sobre la parrilla. Con esta disposición podría conseguirse una nueva economia de combustible. Aunque este sistema de cocción puede ser interesante para las fábricas de cemento con materias primas normales (en Dotternhausen tienen ciertas ventajas por funcionar con pizarras bituminosas), depende de la adaptación funcional de la novedad y los gastos de inversión comparados con la instalación de hornos rotatorios.

El desarrollo de los grandes hornos rotatorios se ha fomentado considerablemente por el invento del enfriador de parrllla (26), puesto en el mercado por la casa Fuller. La casa F. L. Smidth ha desarrollado para sus hornos una construccón especial y propia (Folax), y Polysius construyó para sus hornos Lepol un enfriador con los mismos elementos construetivos empleados para la parrilla Lepol (Recupol). La mayoria de los hornos, incluso los grandes hornos Lepol, aparecen equipados con enfriadores Fuller, fabricados en la República Federal Alemana por la casa Cl. Peters. Además del enfriador normal con parrilla inclinada se construye para los hornos grandes el enfriador horizontal, que ahorra $2,5 \mathrm{~m}$ de altura. Como es de importancia decisiva la marcha del aire para la recuperación de calor y duración de los elementos del enfriador, cada cámara de refrigeración va equipada con un ventilador independiente; con ello, también puede graduarse mejor la marcha del proceso.

Las trituradoras de clinker, sobre todo el ancho del enfriador, se han convertido en elementos imprescindibles del proceso. Los grandes enfriadores tlenen un dispositivo de expulsión en el canal de alimentación del enfriador para eliminar las "bolas", ya que no es posible efectuar este trabajo a mano. Los enfriadores de parrilla presentan las siguientes ventájas; una radiación de calor más reducida, un precalentamiento elevado del alre secundario y la posibilidad de una elevada sobrecarga, a lo que tamblén hay que ahiadir, en los hornos de reducldo consumo de calor, la recuperación del calor del clinker de la salida de aire del enfriador.

\section{Alimentación del hogar del horno rotatorio}

El hogar de los hornos rotatorios ha sufrido un nuevo desarrollo al aparecer el acelte pesado $y$ el gas naturai en el mercado europeo. El cambio a este combustible resulta muy tentador, ya que no requiere ninguna preparación previa en comparación con el carbón; a pesar de esto, no se aprecia una transformación completa en este sentido en las fábricas alemanas de cemento. En USA, el año 1957, todavía se alimentaba un $66 \%$ de los hornos rotatorios con carbón (3); el gas natural se empleaba en el $9 \%$ de los hornos, y solamente un $6 \%$ se alimentaba con aceite. El $19 \%$ restante se alimentaba con una mezcla de combustibles: carbón con aceite o con gas natural. En Alemania, 16 fábricas alimentan los hornos rotatorios con aceite o con carbón y aceite mezclados.

El hogar de aceite (27) de los hornos rotatorios se ha perfecionado con el tiempo. Mientras que en los inyectores antiguos se empleaba vapor o aire comprimido para la pulverización del aceite, en los nuevos inyectores este combustible se pulveriza finamente con inyectores de presión (28) que proporcionan una combustión completa, resultando el consumo de calor no superior al de carbón en polvo (22). Como los quemadores solamente precisan de 2 a $3 \%$ del aire de combustión como alre de refrigeración, el alre primario es más reducido y el aumento de la cantidad del aire secundario mejora la recuperación de calor del clínker, consiguiéndose un ahorro de energía calorifica.

Para el hogar con carbón en polvo surgió como molino soplante el molino Fuller-Peters, que vino a Europa después de la guerra y se encuentra montado en USA en un $60 \%$ de los hornos alimentados con carbón. Frente a una instalación central de molienda con silo intermedio, el molino soplante tiene la ventaja de su sencillez y mayor seguridad. Por-el contrario, tiene peor adaptación cuando hay que cambiar el tipo de carbón. El proceso de secado y separación en un molino exige una cantidad de aire-soporte relativamente elevada; con ello, la cantidad de aire primario del horno se convierte en una considerable desventaja para la cantidad del aire secundario, y la recuperaclón del calor del clínker se ve reducida en unas $25 \mathrm{kcal} / \mathrm{kg}$ de clínker. De unos 20 hornos que trabajan en la República Federal Alemana con molinos soplantes, en gran número de ellos, por el motivo antes indicado, se ha cambiado el proceso normal por un funclonamiento con depósito intermedio. 
Las instalaciones centrales de molienda con depósitos se deben utilizar preferentemente, sobre todo por no poder apreciar si en un plazo muy breve puede ser interesante la combustión conjunta con aceite pesado y hasta con gas natural.

Para las instalaciones centrales de molienda se emplea, además de los molinos tubulares y los acreditados molinos Loesche, el molino Fuller-Peters (fig. 31), después de la introducción del nuevo tipo EM con un número inferior de revoluciones, bolas mayores, una mayor presión de molienda (de un 35 a $50 \%$ ) y un mayor rendimiento en comparación con los modelos antiguos (el modelo mayor tiene una producción de hasta $50 \mathrm{t} / \mathrm{h}$ ). En instalaciones centrales de molienda, estas grandes unidades poseen la ventaja de la sencillez y, por consiguiente, se pueden automatizar fácilmente.

\section{Hornos verticales}

En el grupo de hornos para el proceso por vía seca se incluyen también los hornos verticales modernos de alto rendimiento, cuyo consumo de calor se ha mejorado considerablemente. Aparte de los consumos mínimos aislados de $700 \mathrm{ki}$ localorías, un horno de 2,5 metros de diámetro puede mantenerse en un trabajo continuo produciendo 180 toneladas por día $(29,30)$. Con una buena homogeneización del crudo y con cintas dosificadoras para el crudo y el carbón, se puede cocer un clínker de primera calidad.

La casa Barbarossa, especialista en la construcción de hornos verticales, equipa sus hornos con parrillas giratorias. E! crudo se granula con el combustible por medio de platos.

La casa Loesche ha adquirido los derechos de realización del procedimiento de crudo negro de Spohn (fig. 32), en el que los hornos van equipados con la parrilla giratoria de Spohn. Se cree que con esta parrilla los hornos con tres metros de diámetro y mayores pueden conseguir perfectamente una producción de 250 toneladas/día. Aunque este procedimiento exige una preparación cuidadosa del material y buenos dispositivos de dosificación complican un tanto el trabajo, este horno vertical será interesante para muchos usuarios.
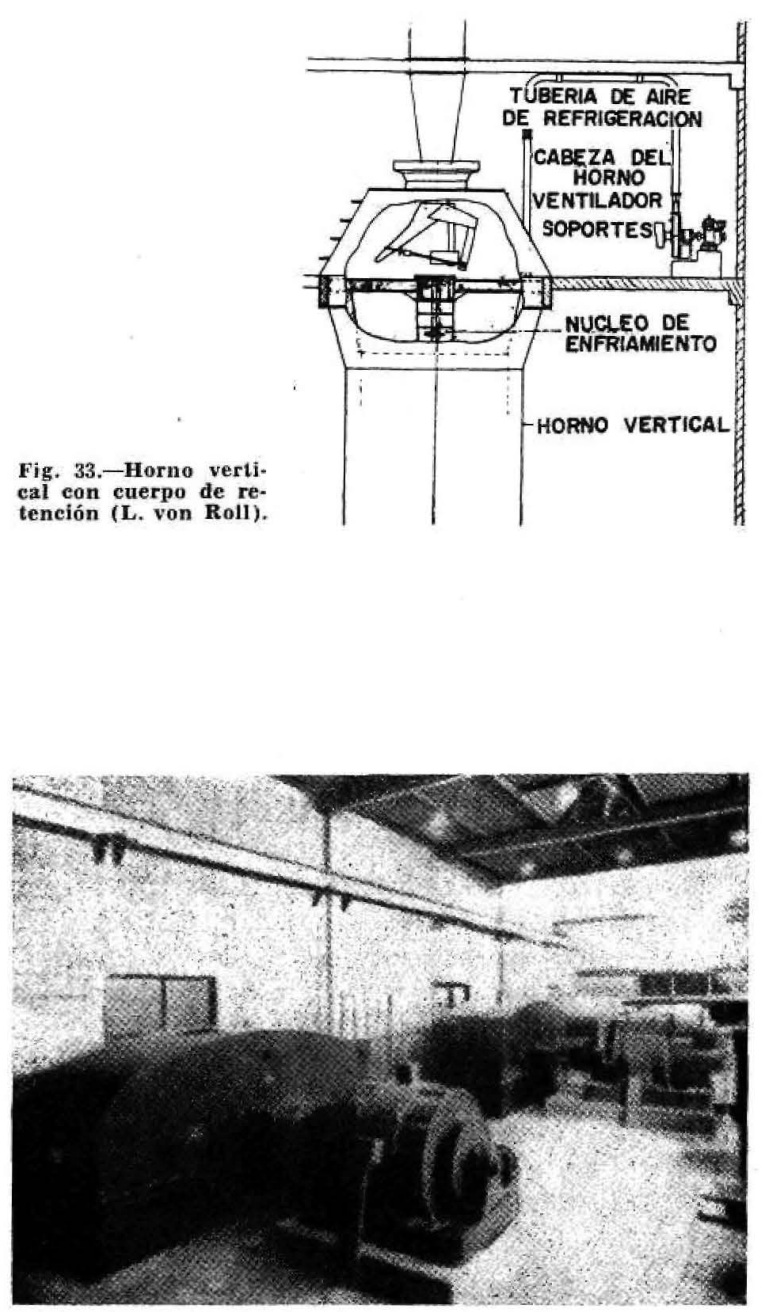

Fig. 34.-Simetromecanismo, $1.600 \mathrm{~kW}$ (F. L. Smidth).

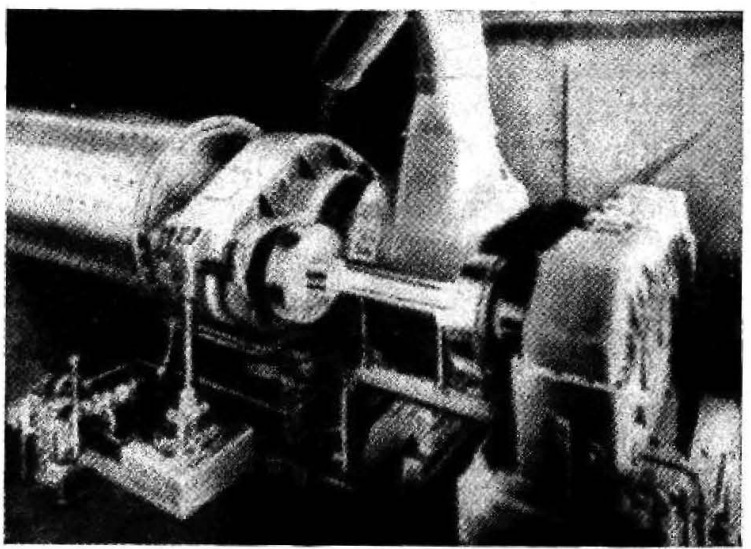

Fig. 35,-Accionamiento doble (Polysius y wílfel). 
La L. von Roll AG ha introducido en los hornos verticales para cemento el cuerpo refrigerado de expulsín (fig. 33) en la parte superior del eje del horno, con objeto de evitar el desprendimiento de clinker en el eje del horno. Un horno de este tlpo, que la fábrica suministradora lo ha equipado con los correspondientes dispositivos de dosiflcación de procedencia suiza, se encuentra instalado hace algunos meses en una fábrica de Westfalia con un funcionamiento satisfactorio. La distorsión de la columna del material en el centro del horno aumenta la velocidad de la cocción, con lo que la producción del horno de $2,4 \mathrm{~m}$ aumenta por día hasta 200 toneladas. En esto se tiene que considerar que el combustible se tritura previamente a $6 \mathrm{~mm}$, de forma que queda envuelto por el crudo con toda seguridad. Von Roll ha montado fábricas completas con hornos verticales, basandose en la ldea de este modelo, disponiendo una amplia automatización. Este tipo de instalaciones se ha tratado preferentemente en paises de ultramar para el montaje de instalaciones nuevas.

En la República Federal Alemana existen todavia 20 fábricas equipadas solamente con hornos verticales y 22 fábricas de cemento en las que, al lado de los hornos rotatorios, trabajan hornos verticales que representan un complemento económico y de valor para los hornos rotatorios, ya estas fábrlcas pueden adaptarse con más facilidad a las exigencias del mercado. El desarrollo de los hornos verticales, que hemos tratado en forma breve, es, en consecuencia, un problema vital para las fábricas pequeñas $\mathrm{y}$ de típo medio por lo anteriormente expuesto, que no debe restringirse en ninguno de los casos, como; por ejemplo, por la obligada parada durante los domingos.

\section{Molinos para cemento}

El desarrollo de las instalaciones para la molienda de cemento ha avanzado muy de prisa en los últimos años, de tal forma que el estado de hace dos afios ha sido renovado por completo (23). Para producciones de molienda elevadas ya no se montan máquinas para molienda grosera y molienda tina, ya que no es fácil coordinar ambos procesos. La industria de la maquinaria ha ampliado sus talleres, hasta tal punto que, en la actualldad, estí en disposiclón de construir molinos con un arrastre de $2.000 \mathrm{~kW}$. Esto permite construir molinos de varias cámaras con un diámetro de $3,6 \mathrm{~m}$ y una Iongitud de $11 \mathrm{~m}$, los cuales, con una buena aptitud a la molienda del clínker de horno rotatorio, pueden alcanzar una producción de 80 t/hora. En el extranjero estos molinos ya están en funclonamiento, y en la República Federal la casa F. L. Smldth está construyendo, en la actualidad, varias instalaciones de molienda accionadas por un simetromecanlsmo muy sencillo (fig. 34). Se consigue un grado elevado de flnura con circuito cerrado de elevador de cangllones y con separador de aire, trabajando normalmente con un Blaine de $2.600 \mathrm{~cm}^{2} / \mathrm{g}$. La captación de polvo se obtlene mediante un pequefio filtro eléctrico para $0,3 \mathrm{~N} \mathrm{~m}^{3}$ de aire por kilogramo de cemento.

Con estos avances quedan anticuados los molinos de cemento de 3,20 ó $3,40 \mathrm{~m}$ de diámetro suministrados en los últimos años por la tindustria alemana de maquinaria para cemento, pero entretanto wïlfel y Polysius han desarrollado nuevos mecanismos gemelos que disponen de un dimensionamiento aceptable para elevados rendimientos de accionamiento de los piñones para la transmisión de momentos elevados de giro. El acclonamlento gemelo (fig. 35) presenta, por su dispostción especlal, la ventaja de descargar el material por el interior del muñón.

Con este ritmo de desarrollo podemos esperar pronto molinos de $3,8 \mathrm{~m}$ con $2.500 \mathrm{~kW}$, que alcancen una producción de 100 t/hora. Estas instalaclones de mollenda de cemento con una producción elevada resultan simples en su construcción y, como consecuencia, se pueden automatíar fácilmente, siendo un punto de vista muy importante respecto a la economia en este tipo de inversiones elevadas.

Para la molienda flna de cemento, con un Blaine superior a $3.500 \mathrm{~cm}^{2} / \mathrm{g}$, el separador de aire se convlerte en una parte imprescindlble de los grandes molinos. Es muy grande el número de tlpos que aparecen en el mercado. La casa WEDAG construyó primeramente un dispositivo con rueda de aletas en sentido opuesto e independiente (fig. 36), que permite una graduación simple de la finura, para lo que se dispuso un motor debajo del separador. Heyd mejoró esta construcción con el accionamlento por arriba de la rueda de aletas en sentido opuesto, y sobre todo, con la allmentación lateral del material a separar (flg. 37), lo que en los tipos grandes consigue un ahorro de algunos metros en la altura de la construcción. Este nuevo separador. que se puede regular eléctricamente, se ha introducido bien y se ha acreditado de mejor forma. También la fábrica Barbarossa, el más antiguo fabricante de separadores de aire, ha considerado este nuevo punto de 


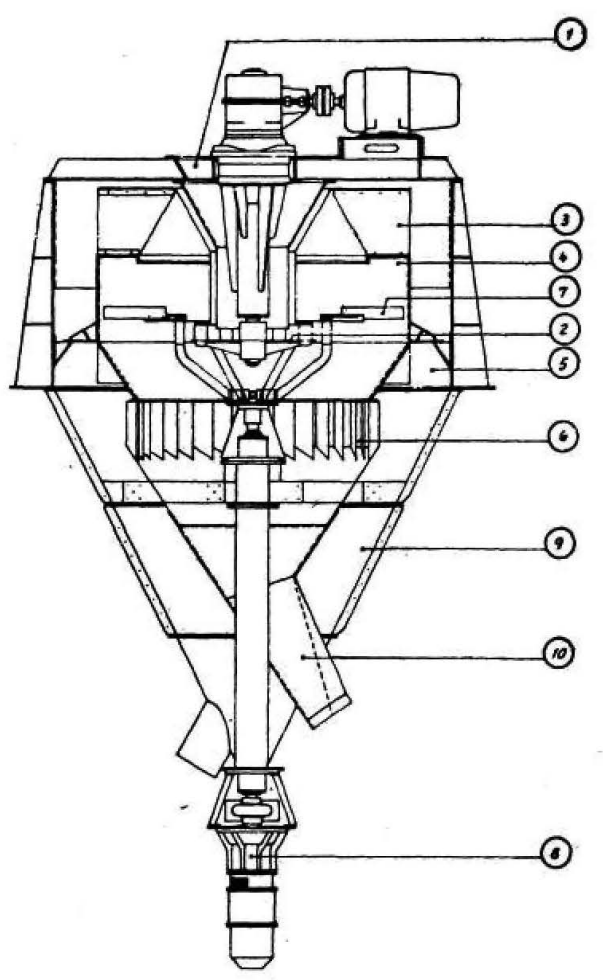

Fig. 36.-Separador de, aire con accionamiento inferior de la rueda de aletas de efecto contrario (WEDAG).

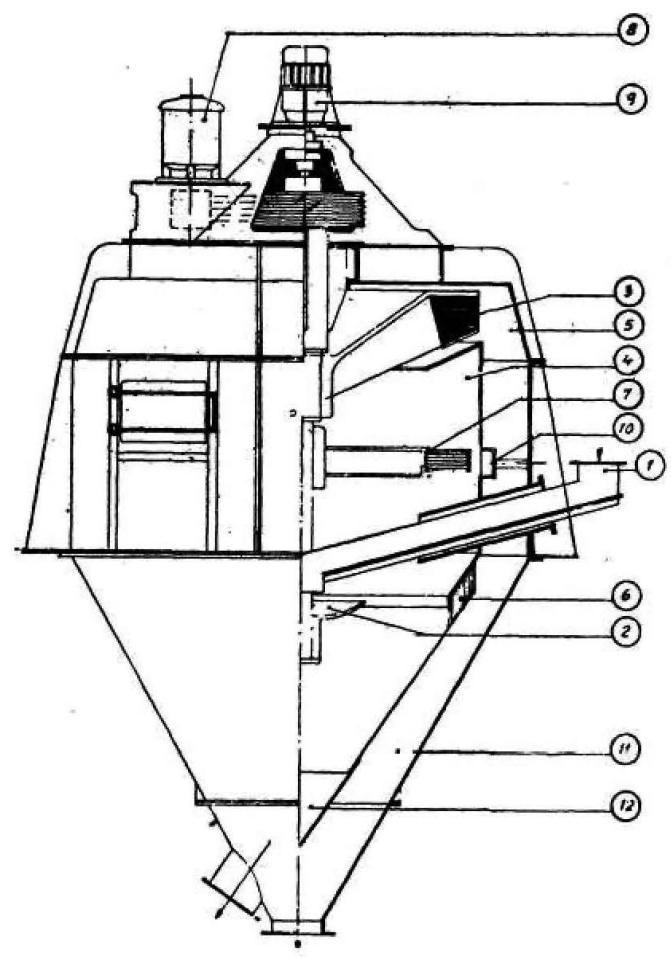
Fig. 37.- Separador de aire con accionamiento
superior de la rueda de aletas de efecto contrario (Heyd).

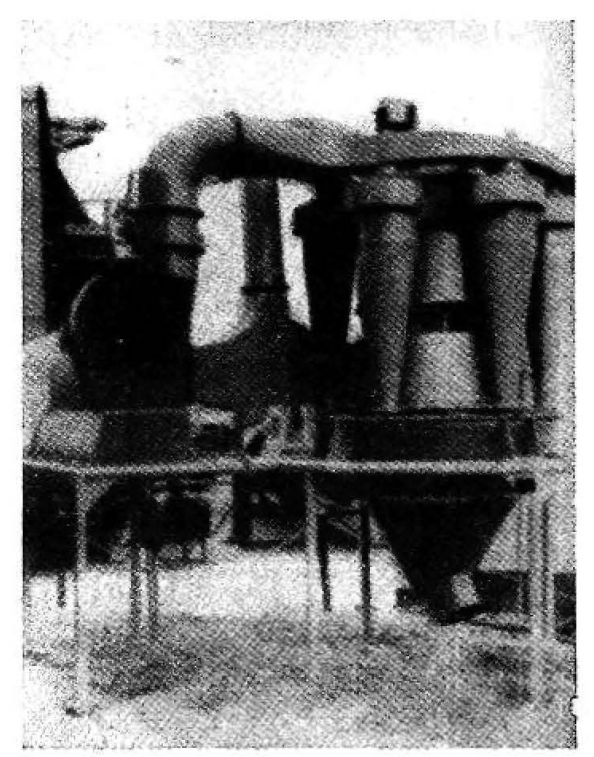

Fig. 38.-Separador de aire con circuito cerrado (WEDAG).

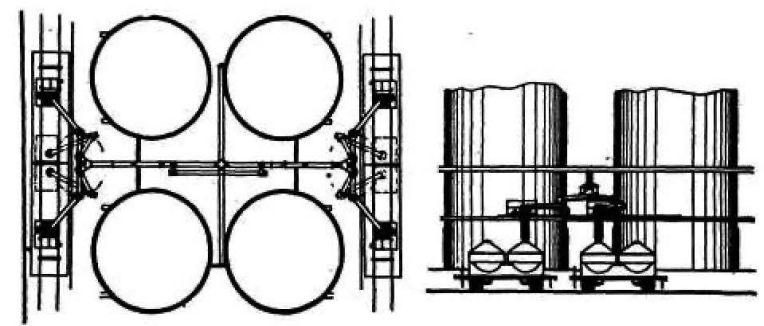

Fig. 39.-Canalón de transporte giratorio para la carga de cemento a granel (Cl. Peters).

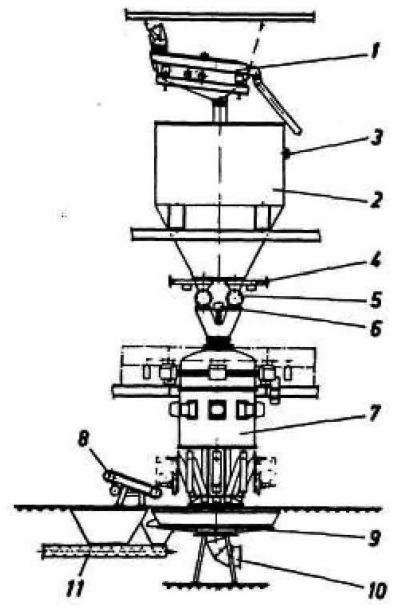


vista. Polysius, Saint-Jacques y otras firmas se esfuerzan en buscar soluciones completamente nuevas. Por ejemplo, la WEDAG dispone la soplante para el movimiento de aire en circuito cerrado hacia el exterior (fig. 38) y capta el material fino separado en cuatro ciclones pequeños en el perimetro de la zona de separación, por una parte, por motivos técnicos de las corrientes y, por otra parte, por perseguir una mejor selectividad.

Hace poco tiempo se ha publicado un amplio informe sobre este tema y sobre el desarrollo de nuevas construcciones (36).

Desde el punto de vista técnico estos separadores de aire presentan la ventaja de que el material se enfría en el circuito cerrado. La molienda fina en una zona de temperatura por debajo de $\operatorname{los} 100^{\circ} \mathrm{C}$ reduce la reslstencla a la molienda (32), por cuyo motivo se disponen otros dispositivos de enfriamiento en el circuito cerrado del material (33), o se inyecta agua pulverizada en la cámara de molienda fna, para conseguir, por todos los medios, una reducclón del consumo especiflco de energía.

El desarrollo de las instalaciones para moler cemento sigue estas soluciones. Los ensayos de funcionamiento tendrán que mostrar qué ventajas presentan las grandes máquinas desde el punto de vista técnico de la molienda. Las pocas comprobaciones realizadas hasta estos momentos han dado los mejores resultados en la aptitud a la molien da.

\section{Ensacado y cargo}

Recientemente ha informado W. Frankenberger, con mucho detalle (34), sobre la nueva disposición de las instalaciones de ensacado y carga. La casa $\mathrm{C}$. Peters ha desarrollado un sistema giratorio de aerodeslizador (fig. 39) para la más rápida realización del suministro a granel, que acelera la carga en recipientes, cuando se dispone una buena salida de atre.

En ei pasado año, la casa F. L. Smidth ha conseguido la ensacadora circular de mayor rendimlento. Entretanto, la casa Haver \& Boecker ha montado en una fábrica de cemento de la provlncia de Westfalia una ensacadora clrcular de sels bocas para 1.500-1.600 sacos (35) (fig. 40), que equipada con ocho bocas puede cargar mảs de 2.000 sacos en una hora. Estas dos instalaciones resultan naturalmente muy costosas o, mejor dicho, más costosas que las ensacadoras automát1cas en linea de cuatro bocas, pero permiten una cumplimentaclón más rápida por parte de los ensacadores.

La tendencia a conseguir un cemento refrigerado o enfriado ha originado que algunas fábricas hayan dispuesto enfriadores que enfrían el cernento desde $100-120^{\circ} \mathrm{C}$ hasta unos $50-60^{\circ} \mathrm{C}$. F. L. Smidth ha construido enfriadores verticales para $30 \mathrm{t} / \mathrm{h}$ con ducha de agua, de $2 \mathrm{~m}$ de diametro y una aitura de 5 a $6 \mathrm{~m}$. Fuller y Lurgi construyen, para este fin, serpentines refrigerados por agua, que no son tan efectivos.

La casa Holderbank ha desarrollado un nuevo enfriador para cemento, que aparece como un conducto neumatico de transporte, en cuyo interior cuelgan unos elementos con circuito de agua. Este aparato, no muy costoso, lo construye la casa Beumer de Beckum (fig. 41).

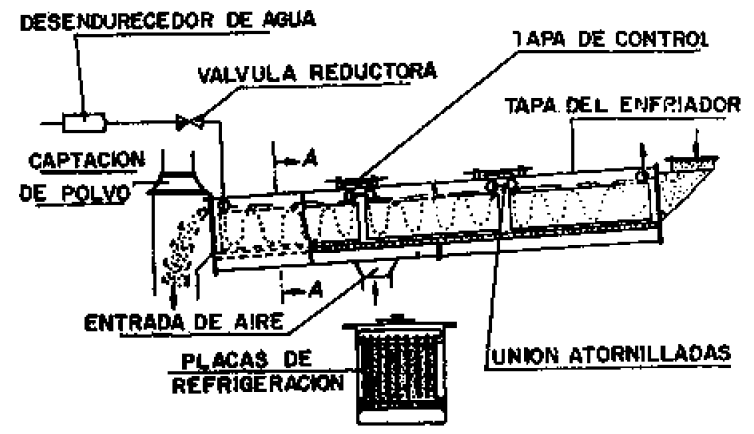

Fig. 41--Enfriador de cemento Holderbank (Beumer). 


\section{Observaciones finales}

Tomando como punto de partida las exigencias del mercado, que son las que marcan el desarrollo de las fábricas, se han mostrado las influencias que determinan el desarrollo de los dispositivos mecánicos de nuestras fábricas.

Partiendo de esta base se han intentado destacar las tendencias en el desarrollo de la maquinaria siguiendo las. fases de la fabricación del cemento, tratando únicamente los elementos importantes y sin considerar los detalles constructivos ni tampoco los productos que se encuentran en el mercado. Por este motivo deseamos recalcar que una descripción más amplia o más breve de la maquinaria y los procedimientos, así como también la circunstancia de no haber indicado algunas fábricas, no quiere decir en ningún caso que esto representa una valoración de mejores aptitudes o de peores propiedades. No es posible tratar este amplio tema con detalle en un informe breve, siendo el fin de este artículo ofrecer a grandes rasgos una información general de la maquinaria más importante para la elaboración del cemento, que nunca ha presentado un desarrollo tan precipitado como en los últimos años.

\section{jografía}

(1) BoмkE, K.: Kohle und Zement. Sonderausgabe Nr. 6 der "Zeitschrift Zement-Kalk-Gips", Wiesbaden, 1958.

(2) Plassmann, E.: Beitrag zur Wärmewirtschaft von Naßdrohöfen. "Zement-Kalk-Gips", 10 (1957), 41-46.

(3) Clausen, F. C.: Der heutige Stand der Zement-Industrie in Nordamerika, Beton 8 (1958), 47-51.

(4) NIKander, B.: Cement production skyrockets in Soviet Russia. "Rock Products", 63 (1960), 6; 102, 104, $106,108$.

(5) Meschter, E.: One man controls two cement plants. "Rock Products", 63 (1960), 3; 80-85.

(6) Flachsengerg, P.: Anpassung der Arbeit an den Menschen. "Zement-Kalk-Gips", 13 (1960), 249-259.

(7) Mrndermann, H.: Höchste Wirtschaftlichkeit in einem Steinbruch mittlerer Leistung durch geeignete Mechanisierung. "Steine und Erden", 70 (1960), 55-63.

(8) STUMPF, K.: Großbohrlochsprengungen in den Vereinigten Staaten. "Steine und Erden", 69 (1959), 203-209.

(9) ERLER, A.: Drehbohrmaschinen für den Steinbruchbetrieb. "Zement-Kalk-Gips", 10 (1957), 196-202.

(10) Stumpr, K.: Baggergroßen, Leistungen und Kosten. "Zement-Kalk-Gips", 10 (1957), 498-500.

(11) Glatzer, G.: Neue Ergerbnisse der gleislosen Förderung. Schriftenreihe des Bundesverbandes der Deutschen Kalkindustrie e. V. Heft 3 (1958), 109-140.

(12) Verein Deutscher Zementwerke e. V. Merkblatt MT 18, Hammerbrecher, febrero 1959. 
(13) SтCMPr, K.: Erfahrungen mit Bandtransporten im Steinbruch. "Schriftenreihe des Bundesverbandes der Deutschen Kalkindustrite e. $\mathrm{V}$. Heft"; 3 (958), 75-87.

(14) Rowland, C. A.: Wet Grinding-past, present, future, "Rock Products", 61 (1958), 8; 102, 104, 106, 108, 110, -119.

(15) Bond, F. C.; Action in a rod mill. "Engineering Mining Journal", 61 (1960), 3; 82-85.

(16) Wkek, P.: Wärmelbergang und Wasserverdampfung beim Naßarehofen. "Zement-Kalk-Gips", 12 (1959! 208-223.

(17) LYDakrs, N.: Le nonveau four rotatif de la $S$. A. des Ciments dobourg. "La Technique des Travaux", 1955,314

(18) EIGEN, H.; Der thermische Wirkungsgrad des Zement-Naßdrehofens. "Tonindutrie-Zeitung", 83 (1959), $474-476$.

(19) KaMINsкx, F.: Uber Lagerungen und Längsfïhrungen von Drehöfen. "Zement-Kalk-Gips", 4 (1951), 322327.

(20) Voos, E., und Blattow, B.: Das pneumatische Homogenisieren. "Zement-Kalk-Gips", 12 (1959), 519-529.

(21) WEBkR, P.: Praktischer Grenzwert des Wärmeverbrauchs von Trockendrehöfen mit Vorwärmer. "Zement-Kalk-Glps", 11 (1958), 543-549.

(22) RupPER, G.: Fortschritte in der Ausnutzung der Abuärme von Trockendrehöfen. "Zement-Kalk-Gips", $13(1960), 366-375$.

(23) BELLWINEEL, A.: Neuzeitliche Mahlanlagen. "Zement-Kalk-Gips", 12 (1959), 41-55.

(24) Goss, C.: thber das Verhalten der Alkalien betm Zementbrennen, "Bchriftenreihe der Zementindustrie, Fielf, 24, Düsseldorf, 1960 .

(25) Clausea, C. F.: Low alkali cement from high-efficiency kilns, "Rock Products", 63 (1960)1; $148-154$ u 164.

(26) Verełn Deutscher Zementwerke e. V.: Merkblatt WE 4, Rostkühler für Drehöfen. Octubre 1960.

(27) MichrL, H.: Oelfeuerungen an Zementdrehöfen. "Zement-Kalk-Gips", 9 (1956), $218-223$.

(28) Verein Deutscher Zementwerke e. V:: Merkblatt WE 7, Drehofenfeurungen, Noviembre 1960.

(29) Sporn, E.: Der Zementschachtofen heute. “Zement-Kalk-Gips”, 11 (1958), 345-357.

(30) NARJES, A.: Wo steht der Schachtofen heute? “Zement-Kalk-Gips", 13 (1960), 409-418.

(31) WhITE, C. A.: African cement firms took a look-then when to vertical kiln. "Rock Products", 60 (1957), 10 ; $108-111$ y $187-188$.

(32) TaKemoto, $\mathrm{K}$; Iro, $\mathrm{I}_{\text {, }}$ und HIRAYAMA, $\mathrm{K}$.: The effect of grinding temperature on the grindability and the quality of Portiand cement. "Reports of Japan Cement Engineerong Assoclation", 1958, 23-25. (Kurzfassung).

(33) Kolв, E. R.; Cement cooling in the grinding ch'cutt. "Rock Products", 59 (1956), 118-129.

(34) FRaNkeNgergen, W.: Verpacken und Verladen in Zementwerken, "Zement-Kalk-Gips", 13 (1960), 1-16.

(35) KRogbetMKer,,$G_{.:}$Ein neuer Rundpakket, "Zement-Kalk-Gips", 13 (1960), 360-363.

(36) FLEcK, K.: Streu-Wtndstchter. "Zement-Kalk-Gips", 13 (1960), 501-522. 